\title{
Characterization of Acoustic Reflex Latency in Females
}

\author{
Reena Narayanan* \\ Master in Clinical Audiology \& Hearing Therapy, School of Advanced Education Research and Accreditation, University Isabel l, Spain
}

Submission: October 05, 2017; Published: October 16, 2017

*Corresponding author: : Reena Narayanan, University Isabel l, Spain, Tel: 34 964847666; Email: reena.aud11@gmail.com

\begin{abstract}
Acoustic Reflex Latency (ARL) is the time interval between onset of an intense auditory stimulus and onset of middle-ear muscle contraction. Unlike pure tone audiogram, the usual procedure to detect middle ear disorders and conductive hearing loss, ARL can differentiate between cochlear and retrocochlear pathologies, yields information about the nature of the conductive disorder, can detect mild conductive problems and is useful for patients that require cooperation. The present study done on 30 normal-hearing female subjects between the age range of 20-30 years old shows no significant differences between the results in the left and right ears of the subjects using the Acoustic Reflex Threshold (ART) latency parameters tested from $500 \mathrm{~Hz}$ to $4,000 \mathrm{~Hz}$ and the Interaural Latency Difference (ILD) for initial latency of $500 \mathrm{~Hz}$ with ILD for initial latency of other frequencies. The present study might be used as normative data for future research on ARL in patients with various cochlear and retrocochlear lesions as part of a differential diagnosis.
\end{abstract}

Abbreviations: ARL: Acoustic Reflex Latency; ART: Acoustic Reflex Threshold; ILD: Interaural Latency Difference; TM: Tympanic Membrane; BBN: Broad Band Noise

\section{Introduction}

Hearing, or auditory perception, is the ability to perceive sound by detecting vibrations, changes in the pressure of the surrounding medium through time, through an organ such as the ear. Sound may be heard through solid, liquid, or gaseous matter. It is one of the traditional five senses. In humans and other vertebrates, hearing is performed primarily by the auditory system. Mechanical waves, known as vibrations are detected by the ear and transduced into nerve impulses that are perceived by the brain, primarily in the temporal lobe. Like touch, audition requires sensitivity to the movement of molecules in the world outside the organism. The process of adaptation to one's environment commences at birth for which integration of information from the various sensations is mandatory. "All the senses contribute to providing a meaning for experiences in life, but hearing and vision, the distances senses are the most crucial»[1]. The human ear is a complex and intricate mechanism fully developed at birth and prepared to react to sound stimuli ranging from very faint to very loud intensities and to the whole range of frequencies that are meaningful to the human environment [1]. Besides communication, our hearing mechanism has several other roles and more subtle functions. Only when one understands these one can truly appreciate what a hearing loss really signifies to an individual confronted by it.

The auditory system consists of the outer ear, middle ear, inner ear, eighth cranial nerve and central auditory nervous system, which includes the auditory brainstem and auditory cortex. The inner ear includes the vestibular system and the cochlea. The eighth cranial nerve includes the cochlear nerve branch and the vestibular nerve branch. The auditory brainstem begins with the cochlear nuclei and proceeding rostrally in the brainstem, it also includes the nuclei and projections of the superior olivary complex lateral lemniscus, inferior colliculus, medial geniculate body and auditory cortex. The auditory cortex is located in the temporal lobe and the right and left auditory cortices are connected by the corpus callosum.

The conductive mechanism includes the outer and middle ears. Conductive hearing impairment refers to hearing impairment from damage to the conductivemechanism. The sensorineural mechanism includes the cochlea, eighth cranial nerve and cochlear nuclei. Sensorineural hearing impairment refers to hearing impairment from damage to the sensorineural mechanism. A central auditory disorder refers to disorder of the central auditory nervous system. Central auditory disorders affecting the brainstem can be classified as extra-axial brainstem or intra-axial brainstem disorders. Extraaxial brainstem disorders affect the cerebellopontine angle at the junction of the eighth cranial nerve and brainstem and the area of the brainstem caudal to the first major decussation.

Thus, extra-axial brainstem disorders of the cochlear nuclei. Intra-axial brainstem disorders affect the brainstem at the first major decussation and in areas rostal to this decussation, including the superior olivary complex caudally and the medial geniculate body rostrally. The term «retrocochlear» refers to disorders of the 
peripheral auditory nervous system including the eighth cranial nerve and extra-axial brainstem. The middle ear should be normal for proper sound propagation from air filled external to liquid filled inner ear. Different pathological condition of the middle ear affects the middle ear function (i.e. middle ear pressure, volume and impedance) differently. Thus, measuring the changes in the middle ear impedance assists in detection of middle ear pathologies. Earlier the only available test to detect middle ear problems and conductive hearing loss was by measuring the air bone gap seen on the pure tone audiogram. A limitation of air-and bone conduction testing is its inability to differentiate between cochlear and retrocochlear pathology. Another limitation is that air - and bone conduction test results do not yield information concerning the nature of a conductive disorder. Also, air - and bone conduction testing is often insensitive to mild conductive problems. Finally, the testing requires patient cooperation which is often difficult to obtain, particularly in neonates, the mentally retarded, the developmentally disabled, and the multiply handicapped.

\section{Hence impedance measurements are used for differential diagnosis of:}
a) Middle ear pathologies.
b) Seventh nerve function.
c) Differential diagnosis of sensorineural - retrocochlear pathologies.

d) As a screening device.

e) For prediction of hearing sensitivity.

Admittance measurements reflects the 'ease' with which sound flows across the structures of middle ear rather than the stiffness or resistance offered to the flow of energy. Thus, the admittance measures the mobility or flow of sound and the impedance, the resistance to the flow of sound, though both measures aims at identifying the pathology and structural abnormalities of the ear. Impedance measurements are performed at the plane of the tympanic membrane (TM). «The measurement of impedance performed at the plane of TM could be static or dynamic» [2]. The static impedance measurement is done under the normal ambient pressure in the ear canal and pressure in the middle ear. The static impedance includes the measurement of compliance and acoustic impedance and they are known as absolute measures [2].

In contrast to static measure, the dynamic measurement includes the measurement of changes in the impedance consequent to the changes in ear canal pressure or contraction of middle ear muscle. Dynamic measures are also known as relative impedance measurements [2]. The measurement of absolute impedance is of little significance clinically [3]. Of the two commonly carried out relative measures - reflex measurements are of greater significance than the tympanometric measures. In this context let us have a brief review of acoustic reflex followed by acoustic reflex latency.

\section{Acoustic Reflex Threshold}

The Acoustic Reflex Threshold (ART) is the lowest intensity of an acoustic stimulus at which a minimal change in the middle ear compliance can be measured. The change in the acoustic immittance of the middle ear as a result of stapedius muscle contraction forms the basis for the acoustic reflex threshold [4]. The acoustic reflex center is situated in the superior olivary complex of the brainstem. There are four acoustic reflex arcs, two ipsilateral and two contralateral [5] (Figure 1). From the reflex pathway, the measurement of Acoustic Reflex Thresholds not only provides information regarding the status of the middle ear system, but also of the auditory nerve, regions of the lower auditory system, and the facial nerve.

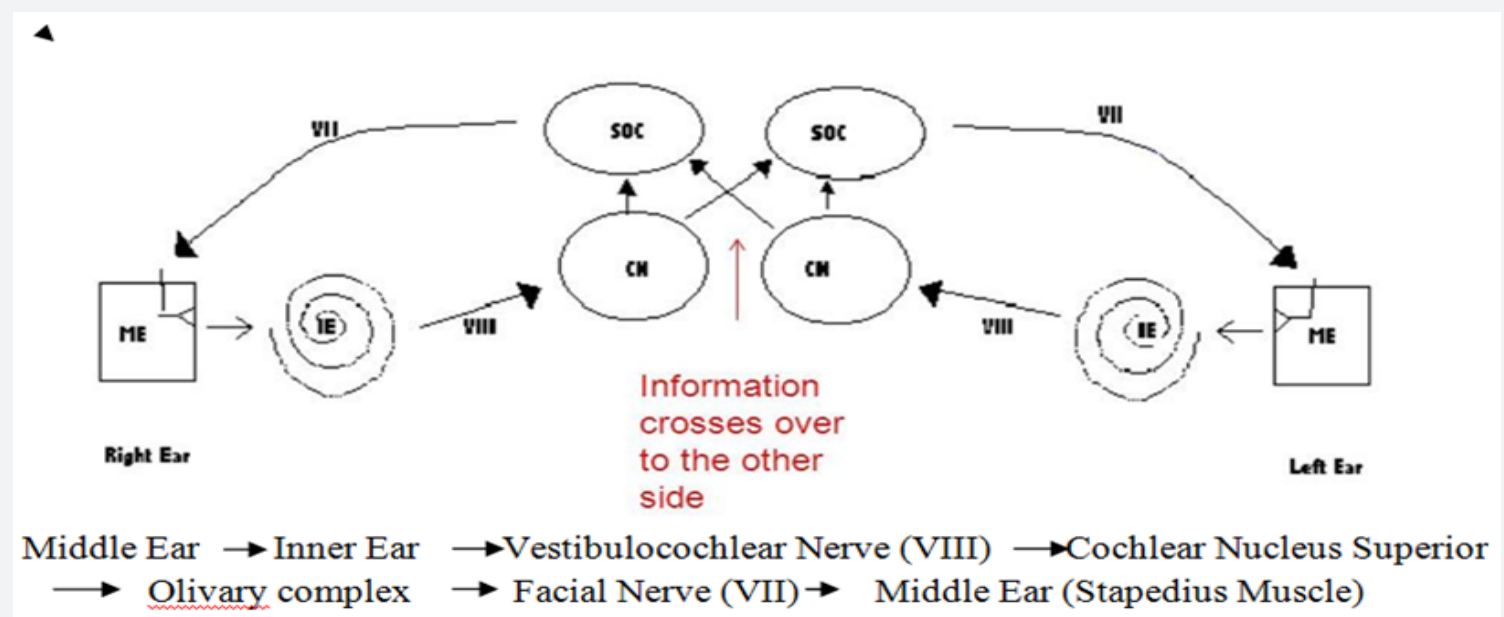

Figure 1: The Model of the Acoustic Reflex Pathway.

The Acoustic Reflex (AR) can be elicited either by an acoustic or non-acoustic stimulation. Due to the bilateral nature of the acoustic reflex arc, the reflex can be measured in the stimulated ear (contralateral measurement). The conventional method for ipsilateral acoustic reflex measurement requires the presentation of two acoustic signals to the same ear, one to elicit the reflex, and one to measure the resulting impedance change (Figure 2). 


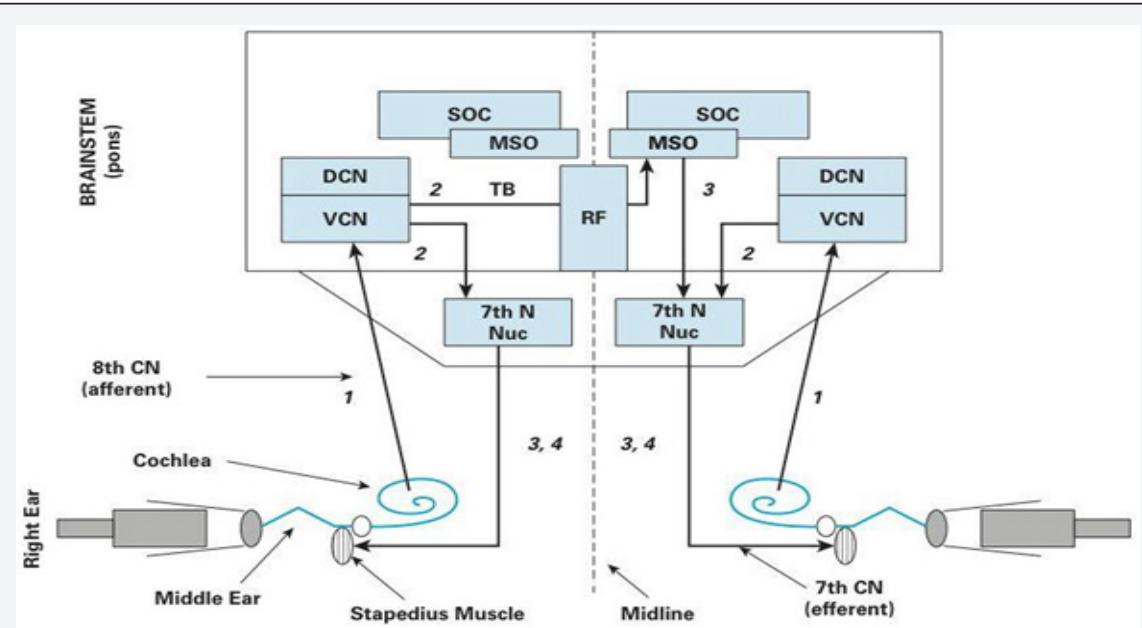

Figure 2: Acoustic Stapedial Reflex Pathways according to Erick Borg (From Hall JW III (2014). Introduction to Audiology Today Boston: Pearson.

The Ipsilateral Acoustic Reflex Threshold: To elicit the ipsilateral acoustic reflex, both the probe tone and activating signals are presented through the probe tube. For the ipsilateral acoustic reflex, the same ear serves as both the stimulus ear (ear receiving the activating signal) and the probe ear (ear in which the acousticreflex response is monitored).

Characteristics of the Ipsilateral Acoustic Reflex: Several characteristics of the AR can be described. These include sensitivity, bandwidth effect and temporal parameters. The characteristics of the ipsilateral reflex are described and contrasted to those associated with the contralateral reflex.

a) Sensitivity: Reflex growth functions may be used to demonstrate the relative sensitivity of the ipsilateral and contralateral acoustic reflex. The ipsilateral acoustic reflex appears to be more sensitive than the contralateral reflex. Equivalent changes in impedance are obtained at lower intensity levels ipsilaterally than contralaterally [6-8]. When reflex threshold is defined as $10 \%$ of maximum impedance change, the ipsilateral reflex is $2-14 \mathrm{~dB}$ more sensitive than the contralateral reflex, depending in part on the frequency of the eliciting stimulus [9].

b) Bandwidth effect: ART decreases with increase in the bandwidth of the reflex-eliciting stimulus. The lower reflex threshold for broad band noise than for tones suggests that the acoustic reflex is related to the bandwidth of the stimulus. Djupesland and Zwislocki [10] found that increasing the separation in frequency between the two tones in a two-tone complex caused a lowering of the reflex threshold once a particular bandwidth was exceeded. These findings suggest that there is a critical band for the acoustic reflex, beyond which widening of the bandwidth results in lower thresholds.

c) Temporal Parameters: Brask [11] demonstrated that bilateral stimulation results in the shortest latencies, that latencies of ipsilateral stimulations are longer, and that with contralateral stimulation, the longest latencies result. Latencies for the three methods (ipsilateral, contralateral and bilateral) result in systematic differences in rise time of the reflex. The latencies ranged from 15 to $100 \mathrm{~ms}$ (stimulus $=1000 \mathrm{~Hz}$ ), which compares reasonably well to latencies derived through the acoustic-impedance method for the contralateral reflex.

Advantages of Ipsilateral Reflex Threshold: According to Green and Margolis [12], ipsilateral reflex measurement is superior to contralateral acoustic reflex measurement in the following ways.

a. The status of one ear does not affect acoustic reflex assessment in the other ear. The ipsilateral test apparatus allows for independent assessment of the two ears. This is an important advantage in many cases. For example, in cases of unilateral conductive pathology, the integrity of the eighth nerve cannot be assessed in the good ear by contralateral acoustic reflex measurement since the presence of a conductive loss in the probe ear will obliterate the acoustic reflex. By ipsilateral acoustic-reflex measurement, however, the ART can be measured in the good ear without the contaminating influence of the conductive loss in the other ear.

b. Acoustic reflex testing can be done on children who refuse to submit the contralateral acoustic reflex testing because of the earphones.

c. Inconsistent placement of the contralateral supra-aural earphone on difficult-to-test subjects probably results in substantial calibration errors. The ipsilateral test apparatus can be positioned more consistently, allowing for lower inter- and intra-subject variability.

d. Another advantage of ipsilateral testing, when used in conjunction with contralateral testing is related to the assessment of the eighth nerve and auditory brainstem disorders [13-16]. Different ipsilateral-contralateral patterns can be related to various loci of pathology. An eighth nerve lesion typically presents an absent ipsilateral acoustic reflex on the affected side but a normal contralateral reflex when the normal ear is stimulated. A midline brainstem lesion, which 
does not affect the ipsilateral pathways, is characterized by normal ipsilateral reflexes in both ears and absent contralateral acoustic reflexes bilaterally.

\section{Disadvantages of Ipsilateral Reflex Threshold}

The several inherent problems in ipsilateral acoustic reflex measurement include artifacts, and reduced maximum output intensities.

Artifacts: In ipsilateral acoustic reflex measurement, the probe tone and eliciting signals are presented through the same tube (same ear), creating the potential for the signals to interact acoustically. The interactions are undesirabe, because they produce artifacts, which may obscure the reflex, or the artifacts themselves may be misinterpreted as actual acoustic reflexes. Two ipsilateral measurement artifacts have been described - the additive and the eardrum (or subtractive) artifacts $[17,18]$. The additive ipsilateral artifact results from inadequate frequency separation of the eliciting stimulus and the probe tone. Maintaining adequate frequency separation between the probe and the reflex-eliciting stimulus is, therefore, essential for the avoidance of additive artifacts. The additive artifact can be observed either in an ear or in a hard-walled calibration cavity.

When the probe tone and the reflex eliciting stimulus are presented to the same ear, the eardrum artifact, a second artifact may be observed as an apparent decrease in impedance that is time locked to the eliciting stimulus. The eardrum artifact can be observed only in complaint cavities. The fact that this artifact does not occur in hard-walled cavities suggests that it results from a nonlinear process associated with complaint membranes. Two possible mechanisms that may account for this artifact are intermodulation distortion and visco-elastic properties of membranes like the eardrum $[18,19]$.

The Contralateral Acoustic Reflex Threshold: Acoustic Reflex (AR) can be inferred from monitored changes in the acoustic immittance of the ear. Thus, the Acoustic Reflex Threshold (ART) may be defined as the lowest level of a stimulus (activator) that produces a measurable change in acoustic immittance of the middle ear (or its components), resulting from contraction of the stapedius muscle; this acoustic immittance change is time locked with the stimulus. In Contralateral Acoustic Reflex Threshold, the auditory stimulation is presented through an earphone to one ear and the immittance change is monitored in the opposite ear. Contralateral ART, unlike the ipsilateral ART, is relatively free of artifacts and calibration problems.

\section{Normal Acoustic Reflex Thresholds}

The acoustic reflex is the contraction of the stapedius muscle of the middle ear in response to an acoustic activating signal. This contraction can be monitored by recording the resultant change in the acoustic immittance of the middle ear. The change in the acoustic immittance of the middle ear as a result of stapedius muscle contraction forms the basis for the acoustic-reflex threshold and acoustic reflex decay tests. Numerous researchers have documented that the necessary intensity range to elicit the acoustic reflex at threshold for normal-hearing subjects is 70 to $100 \mathrm{~dB}$ hearing level (HL) [20,21]. The median threshold value for the contralateral stapedial reflex to pure tone signals is approximately $85 \mathrm{~dB}$ HL and $65 \mathrm{~dB}$ HL for broad band noise. Ipsilateral acoustic stimulation results in slightly lower acoustic reflex thresholds [21], The ART is generally established by an ascending and descending $5 \mathrm{~dB}$ increment bracketing procedure to determine the minimal intensity required to note a change in middle ear compliance [22]. ART measurement is usually conducted at test frequencies of 500 1,000, 2,000 and 4,000 Hz. There is little threshold variability for the acoustic reflex for various stimuli among studies of normal listeners, suggesting that the ART is a relatively stable auditory system characteristic [23].

Wilson [24] reported that reflex magnitude for pure tone stimuli is similar across frequencies, although the greatest mean reflex magnitude is observed with broad band noise. The duration of the activating signal should not be too short or too long. Silman and Gelfand, 1982 suggest that activators lasting 1 to 2 sec are ideal because with brief activators (i.e. $300 \mathrm{~ms}$ or less), the stimulus must be increased in order to compensate for the reduction in stimulus on-time. Signals longer than 2 secs seem to have little effect. Jerger et al., [25] and Hall and Weaver [26] show that the ART to pure tone stimuli tend to improve slightly with increasing age from 0 to 50 years, but demonstrate no change as a function of age for broadband noise stimuli Silman [27]. Several classic studies demonstrated that normal ART's occur at approximately 85-100 dB SPL for tonal activators and on the order of $20 \mathrm{~dB}$ lower for wide band stimulus [27-33].

Wilson et al. [34] found no significant differences between the left and right-ear ARTS of normal-hearing subjects. In fact, the interaural variability of ART's was about half the intersubject variability. The $80 \%$ normal ranges of interaural differences were $6.3 \mathrm{~dB}$ for $500 \mathrm{~Hz}, 6.9 \mathrm{~dB}$ for $1,000 \mathrm{~Hz}, 7.7 \mathrm{~dB}$ for $2,000 \mathrm{~Hz}$, and 8.3 $\mathrm{dB}$ for BBN. Comparison of Broad Band Noise (BBN) and tonal data reveals that the expected $20 \mathrm{~dB}$ difference is found only among the studies using high resolution method. The disparity is due to the higher noise ART's obtained when $5 \mathrm{~dB}$ steps and/or visual meter monitoring are employed. The major reason for this finding is the magnitude of the immittance change, which occurs just above ART for noise activators [35-37]. The amount of immittance change is very small at ART and does not increase much, if at all, for levels up to about 5 to $10 \mathrm{~dB}$ above ART for the BBN activators. For higher BBN levels, the magnitude of the reflex response increases linearly with BBN activator level.

\section{Low-Level Reflex Thresholds}

Substantially lower ARTs are obtained when facilitating tones are employed. A facilitating tone is one that is presented to the ear at a level just below the ART for the facilitator. The presence of a facilitator result in a reduction in the ART for a test tone with respect to the ART obtained without the addition of the facilitator to the acoustic reflex activator. Lower-than-expected ARTs have 
also been reported using computer averaging of ART's (essentially to improve the signal-to-noise ratio), although this is not a finding common to most studies that have employed computer averaging techniques.

\section{Diagnostic Applications}

a) Conductive Hearing Loss: The ARs are abnormal in conductive pathologies [38-41]. The essential finding across studies is that ARs are either absent or elevated in threshold when there is a middle ear abnormality in one or both ears. Underlying this point are two rather simple concepts. First, if there is a conductive loss in the activator ear, then the effective level of the stimulus reaching the cochlea will be reduced by the amount of that loss; hence the ART will be elevated. Second, in presence of middle ear pathology in the probe ear, then it will not be possible to monitor a change in acoustic immittance from which reflex activity is inferred. The presence of a bilateral conductive disorder thus results in a reduced signal to the cochlea and the inability to monitor the reflex response at both ears. In some cases of otosclerosis, however, it has been reported that ARTs may actually be obtained at lower than expected levels [42]. This finding is commonly referred to as 'conductive recruitment'.

b) Sensorineural Hearing Loss: The classic work of Metz [43] and various investigators have reported that tonal ARTs are similar among normal ears and those with sensorineural loss [43-50]. There is general agreement that ARTS are constant when sensorineural loss is no worse than about 50-55 dB HL [51]. When hearing loss increases beyond this range, one may expect that tonal ART's to increase as well in a fairly regular manner [52-54]. Holmes and Woodford [55] found ARs to be absent among profoundly hearing-impaired children $7.1 \%$ of the time at $500 \mathrm{~Hz}$ and $90-93 \%$ of the time at higher frequencies. There is considerable evidence demonstrating that BBN-reflex thresholds are elevated in cases of sensorineural hearing loss [56-61].

c) Retrocochlear (eighth-nerve) Pathology: The acoustic reflex is useful in differentiating cochlear from eighth nerve disorders in two ways. First, the acoustic reflex is characteristically present in ears with cochlear disorder (below a limiting degree of hearing loss) and characteristically absent in ears with an eighth nerve disorder. Second, when the acoustic reflex is unexpectedly present in an ear with an eighth nerve disorder, it typically exhibits an abnormal time course to sustained signals. Elevated or absent ARs have been repeatedly demonstrated to occur in cases of retrocochlear pathology. When an elevated or absent AR is seen, it should be considered to be pathological in the most significant question in this context.

The criteria proposed by Anderson and Wedenberg [62] include two assumptions: First, ARTs must exceed the $90^{\text {th }}$ percentiles of the ARTs of normal-hearing subjects, and second, the hearing loss of the patient does not exceed $60 \mathrm{~dB}$ HL. A promising indicator of
AR abnormalities in retrocochlear pathology comes from interaural comparisons [63-65]. The diagnostic import of absent ARs must be considered within the limitations imposed by the maximum activator levels used particularly when the $90^{\text {th }}$ percentiles exceed $110 \mathrm{~dB}$ HL. An absent AR at $110 \mathrm{~dB}$ HL should not be viewed as an abnormal finding unless the $90^{\text {th }}$ percentiles for that degree of hearing loss fall at or below $110 \mathrm{~dB}$ HL.

d) Brainstem Pathology: The application of acoustic reflex measurements to the identification of brainstem pathology has focused on a comparison of contralateral and ipsilateral reflex thresholds [66-69]. The absence of contralateral reflexes, with ipsilateral reflexes intact, may be seen in patients with confirmed brainstem pathology. These abnormalities are considered to be the result of the presence of a lesion in the area of the crossed brainstem pathways while the uncrossed brainstem pathways remain intact. Consideration of the presence or absence of crossed and uncrossed acoustic reflexes helps in determining the specific site of lesion in patients with brainstem dysfunction. If the lesions are higher in the auditory pathway, the acoustic reflex finding is likely to be within normal limits or involved in accordance with any hearing loss that might be present.

e) Facial Nerve Disorder: The acoustic reflex is also a valuable tool in the management of seventh nerve dysfunction [70]. The acoustic reflex measurement is helpful in determining the site of lesion of the facial nerve disorder as either distal or proximal of the stapedius branch of the seventh nerve. In the evaluation of facial nerve disorders, the acoustic reflex may be measured with ipsilateral or contralateral stimulation. Interpretation of facial motor disorder is a function of the efferent nerve pathway, so acoustic reflex results are interpreted for the immittance probe ear only. If the acoustic reflex is present at normal HL, the localization of pathology is likely to be distal to the origin of the stapedius branch of the nerve; if the reflex is absent, the disorder is likely proximal to the nerve. If the reflexes are present but elevated, the disorder is likely proximal to the nerve. According to Citron and Adour [71], the acoustic reflex is an efficient indicator of impending nerve degeneration and predictor of recovery. Therefore, reflex testing over the course of several days of weeks may be appropriate. A patient with Bell's palsy may initially exhibit no acoustic reflexes, then present elevated reflexes and finally show normal reflex responses as the disorder gradually resolves to complete recovery.

f) Nonorganic Hearing Loss: Another application of acoustic reflex measurement pertains to the patient suspected of having a nonorganic or pseudohypacusis hearing loss. Studies done on Acoustic Reflexes shows that, the greater the hearing loss, the lesser the likelihood there is of obtaining an acoustic reflex. It is highly unlikely to observe an acoustic reflex at a level less than $15 \mathrm{~dB}$ above the patient's threshold and impossible to obtain a reflex measure at a lower hearing level than the true hearing threshold [72]. The presence of an acoustic reflex suggests that 
true hearing loss is no more than $20 \mathrm{~dB}$ less than the reflex HL. These patients are especially good candidates for the prediction of hearing sensitivity techniques using the acoustic reflex [73].

\section{Advantages of Acoustic Reflex Threshold}

a) The immense value of the acoustic reflex is highlighted by a wide variety of applications in special populations [74].

b) AR is a powerful tool of audiological evaluation.

c) It is an important application of AR measurement in the differential diagnosis of cochlear versus eighth nerve disorder and eighth nerve versus brainstem disorder.

d) The acoustic reflex test is used in diagnostic applications which include facial nerve disorder and neuromuscular disorders like myasthenia gravis.

e) Acoustic reflex measures are helpful not only in localizing the site of a facial nerve disorder, but also in charting facial nerve recovery [75].

f) In very young children, acoustic reflex prediction methods clearly offer the most rapid and viable objective measure of hearing sensitivity. Children at risk for middle ear effusion, such as those with Down's syndrome, cleft lip and cleft palate, craniofacial disorders, and others who are otitisprone are especially suited for evaluation with the acoustic reflex [76]. In such difficult-to-test patients, acoustic reflex prediction methods clearly offer a rapid, efficient, economical and objective estimate of hearing sensitivity.

g) The Acoustic Reflex measures are useful in selecting electroacoustic characteristics. Keith [77] reports that the ART procedure is successful for setting hearing aid gain for children, because in quiet, the ART and MCL for speech are correlated. Seventy-five percent of the hearing aid users reported that they were amplified to their most comfortable listening level.

h) Jerger et al., [78] suggest that the electrically elicited stapedius reflex growth function may provide a basis for estimating cochlear implant electrode dynamic range. Their results showed that the electrically elicited acoustic reflex threshold was in good agreement with preferred listening level, and the acoustic reflex saturation level was usually well below the patient's uncomfortable listening level. These acoustic reflex applications may be especially valuable with the preoperative and postoperative evaluation of potential implant candidates who are too young to make adequate behavioral responses to cochlear implant settings.

i) Metz [79] suggested that AR may indicate presence of loudness recruitment and that it represents an upper boundary of the dynamic range of hearing.

j) In combination, tympanogram and acoustic reflexes, offer a sensitive, easily administered means of assessing middle ear function and cochlear sensitivity in animals.
Objective: Measurement of ARL has been reported in experimental animals [80], normal-hearing subjects and patients with sensory neural hearing loss [81-85]. ARL has been suggested as an indicator in otoneurological diagnosis. It has been found that the interaural latency difference may have diagnostic significance [85]. But before applying ARL to clinical use it is necessary to determine and clearly demarcate what would constitute the presence of a 'normal' response from an 'abnormal' one. The ARL test data obtained from a patient would be meaningless if we do not possess a database of what constitutes a response expected from a normal individual matched for age, sex, etc. Only after performing a comparison between the normal ranges of expected values with that from the subject will one be able to comment with normality or abnormality of the responses obtained from the patient. The present study was conducted to determine a normative data for clinical purposes.

\section{Acoustic Reflex Latency Test (ARLT)}

A. Acoustic Reflex Latency Test is defined as the time for the first detectable impedance change resulting from stapedius muscle contraction following an intense acoustic stimulation, that is, the time interval between the onset of an intense auditory stimulus and onset of middle ear muscle contraction [86].

\section{B. The concept of Acoustic Reflex Latency}

Normal acoustic reflexes can be observed only when several biological preconditions have been met in the subject. These preconditions include:

a) Normal middle ear function

b) Normal auditory nerve function

c) Intact brainstem pathways between cochlear nuclei and superior olivary complex

d) Normal facial nerve function proximal to and including the stapedius branch

e) Hearing sensitivity no worse than about $60 \mathrm{~dB} \mathrm{HL}$

When one or more of these preconditions fails, characteristic abnormalities of the reflex may appear. These abnormalities may be manifested in prolonged onset or offset latencies, amplitude decay, elevated thresholds, aberrant amplitude - intensity functions and/or threshold differences between ipsilateral and contralateral activating signals. The effects of certain signal parameters on characteristics of the acoustic reflex are well known [87]. Increasing intensity for example results in larger amplitude and shorter latency responses. Several variables, however, compound the measurement of reflex latency.

First, the commercially available electroacoustic immittance measurements have various time constants [88-91]. Second, the measurement of reflex latency is complicated by an imprecise definition of the onset of the acoustic reflex. Several researchers vary on the criteria for judging the end of the later recovery period 
(i.e. the onset of the impedance change versus some percentage of the amplitude). To standardize the measurement criteria, some studies [91-94] have arbitrarily fixed this end of the latency period at the point where the acoustic reflex response reaches $10 \%$ of its maximal amplitude. Unlike the precise onset of an activator signal, the onset of acoustic reflex can be monophasic or biphasic, making the reflex latency measurement difficult and arbitrary [95-100].

\section{Latency of the Response of the Acoustic Middle Ear Reflex}

Contractions of the middle ear muscles occur with a certain delay after the onset of a sound stimulus. At a particular point, a certain time elapses after the onset of the tone burst before any discernible impedance change can be seen. This time is called the 'latency time'. The latency time decreases when the stimulus intensity increases. At stimulus levels immediately above the threshold of contraction, the latency has values of 150 to $250 \mathrm{~ms}$; the shortest latency of the contraction of middle ear muscles as an acoustic reflex in man is about $25 \mathrm{~ms}$, which is recorded at stimulus levels $30-40 \mathrm{~dB}$ above threshold $[80,81]$. When measuring latency time of the acoustic middle ear reflex, it is important to make certain that the equipment used to record the reflex response has a response time that is much shorter than that of the reflex. The latency time of the acoustic middle ear reflex is composed of the neural conduction time from the inner ear to the facial nerve motor nucleus, the delay in the nucleus itself, the neural conduction time along the facial nerve, and finally the time which elapses from the arrival of the neural impulses at the muscle to the development of a measurable mechanical contraction in the stapedius muscle. Latency of the muscle action potentials recorded in response to contralateral stimulation is reported to be $10.5 \mathrm{~ms}$ in response to loud sounds [101].

\section{Temporal Integration}

The acoustic middle ear reflex has a certain degree of temporal integration. Studies show that the impedance change increases gradually after the latency time is elapsed. This means that the tension of the muscle develops gradually. This temporal integration has been studied in several ways. Djupesland and Zwislocki [102] studied the sensitivity of the acoustic reflex as a function of the duration of the tone burst used as stimuli. They found that the reflex has a time constant of integration of about $200 \mathrm{~ms}$. Due to the latency of the reflex response and the slow rate with which the reflex response rises when elicited by a tone burst with rapid rise, this reduction in transmission through the middle ear does not affect the sound transmission until a certain time has elapsed after the onset of the sound. As the sound transmission decreases the effectiveness of the stimulus that elicits the middle ear reflex also decreases, as does the tension of the stapedius muscle.

This decrease in tension of the stapedius muscle causes the transmission of sound through the middle ear to increase and, consequently, an increase occurs in the stimulus that elicits the middle ear reflex. The result is that the contraction strength of the stapedius muscle increases again. The integration time of the middle ear reflex with that of loudness area bout $200 \mathrm{~ms}$ at threshold [103]. Measurement of latency of the acoustic reflex must take into consideration the criteria for latency measurement, the signal parameters used, and the interaction of latency with absolute amplitude. In addition, accurate latency measurements require instrumentation that will assure temporal fidelity. The parameters of ARL, which have been used in this study, are initial latency, terminal latency, initial recovery and terminal recovery.

\section{Overview of the Present Study}

Because of the temporal characteristics of the impedance apparatus [104] each should use normative data for specific equipment in determining ARL. The present study has been conducted on 30 normal-hearing females between 20 and 30 years of age. ARL test was done on Resonance Middle Ear Analyzer to further characterize ARL and for the establishment of normative data. This study is the first of its kind conducted at this medical centre. The data from the present study would form a better source of comparison in the context other than results from studies on other age groups.

The purpose of the present study is to further characterize ARL. The following were the null hypothesis proposed for this study:

a) There is no significant difference between the initial latencies of right and left ears for 500, 1,000, 2,000 and 4,000 $\mathrm{Hz}$.

b) There is no significant difference between the terminal latencies of right and left ears for 500, 1,000, 2,000 and 4,000 $\mathrm{Hz}$.

c) There is no significant difference between the initial recovery of right and left ears from 500, 1,000, 2,000 and 4,000 $\mathrm{Hz}$.

d) There is no significant difference between the terminal recovery of right and left ears for 500, 1,000, 2,000 and 4,000 Hz.

e) There is no significant difference between ILD for initial latency of $500 \mathrm{~Hz}$ and ILD for initial latency of 1,000 Hz.

f) There is no significant difference between ILD for initial latency of $500 \mathrm{~Hz}$ and ILD for initial latency of 2,000 Hz.

g) There is no significant difference between ILD for initial latency of $500 \mathrm{~Hz}$ and ILD for initial latency of 4,000 Hz.

\section{Literature Review}

The acoustic test remains a valuable diagnostic tool in today's audiological test battery [104,105]. Acoustic Reflex Latency has been studied for more than 50 years [100] and has been suggested as an indicator in otoneurological diagnosis [101-105]. The effects of certain signal parameters on characteristics of the acoustic reflex are well known [104]. The reflex parameters, which may be reflective of neurotologic disorder has given more attention.

The latency of the acoustic reflex is the time difference, $t$, between the onset of the reflex activator signal and the onset of the 


\section{Global Journal of Otolaryngology}

acoustic reflex. To measure ARL for clinical purposes, the acoustic reflex response must be recorded with a simple but precise method which takes into consideration the fact that the physiological ARL depends upon several factors the model of the instrument, the characteristics of the eliciting stimulus (such as rising the frequency and intensity) and the time constant of the measuring device whether the stimulation is ipsilateral or contralateral and the auditory status of the subject. To make accurate latency measurements of the reflex, the instrument response time must be faster than the middle ear muscle reflex [103].

If ARL measurements are to be made then it is imperative that the temporal characteristics of the instrument are first measured. A suggested procedure for making these measurements was described by Popelka and Dubno [105]. The ANSI (American National Standards Institute, 1982) states that the manufacturer must specify the latency of the instrument and that the temporal response of the instrument should not exceed $50 \mathrm{~ms}$. The International Electrotechnical Commission (IEC) standard further defines «Overshoot» and «Undershoot» and specifies that they should not exceed 10 percent of the maximum response.

a) Overshoot ( $\Delta$ Yao $/ \Delta$ Zao $)$ is the transient artifactual response in the measured value before reaching steady state when the stimulated change in input is switched on.

b) Undershoot ( $\Delta \mathrm{Yau} / \Delta \mathrm{Zau}$ ) is the transient artifactual response in the measured value before reaching steady state when the stimulated change in input is switched off.
According to ANSI (1982), the proposed definitions are identified as change in acoustic immittance $\Delta y$ a or $\Delta$ za (for upper curve) and change in Voltage $\Delta$ vi (for lower curve) are plotted against time (seconds) (Figure 1)

a) Initial latency ( $\mathrm{Li}$ ) is defined as the time (in sec) from the beginning of an instantaneous immittance change to $10 \%$ of the measured steady-state immittance change.

b) Rise time (tr) is defined as the time (in sec) from $10 \%$ to $90 \%$ of the measured steady-state immittance change.

c) Terminal latency (Lt) is defined as the time (in sec) from instantaneous termination of the initial immittance change to $90 \%$ of the measured steady-state immittance change.

d) Fall time (tf) is defined as the time (in sec) from $90 \%$ to $10 \%$ of the measured steady-state immittance change after termination of the initial Immittance change.

The above-mentioned definitions can be combined with standard pulse terms and with wave shaping and distortion definitions to produce a complex verbal characterization of the response waveform. This approach is more descriptive than a scheme that uses arbitrary labels or sequential numbers to identify onset and offset latency points [96-104]. The temporal characteristics of the Acoustic Reflex were expressed according to the terminology suggested by GSI (Grason-Stadler, Inc.), (Littleton, MA, USA). The definitions of some terms used in the present study are as follows: (Figures 3-5).

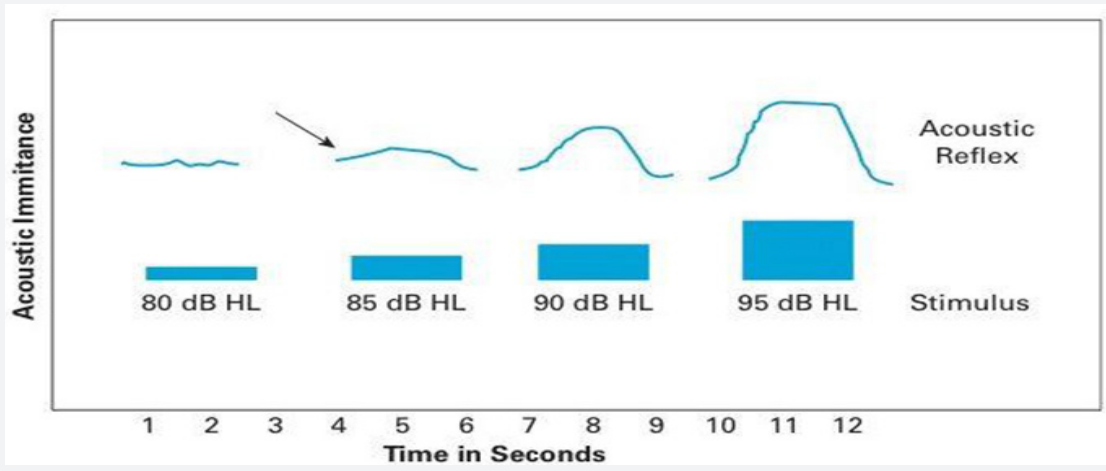

Figure 3: Acoustic Reflex Measurements / Acoustic Reflex Threshold.

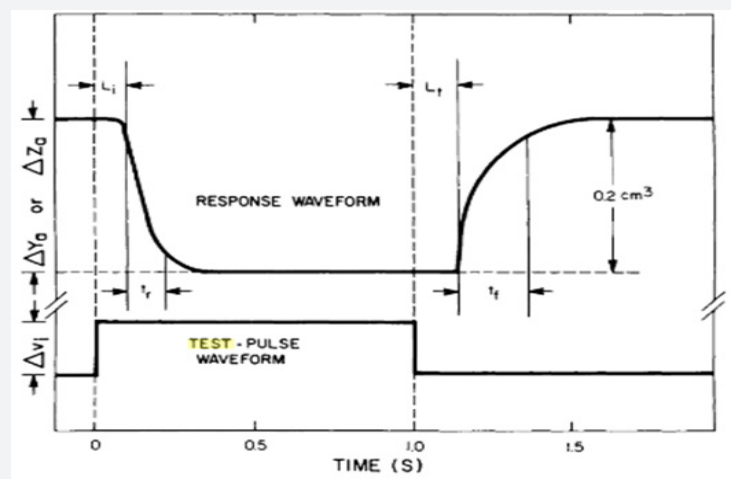

Figure 4: Analog electrical-output waveform (upper curve) from a commercially acoustic -immittance instrument when procedure suggested by Popelka and Dubno (1978) was used to measure its temporal characteristics. Initial Latency Li, Risetime tr, terminal Latency Lt, and falltime, tr are identified. 


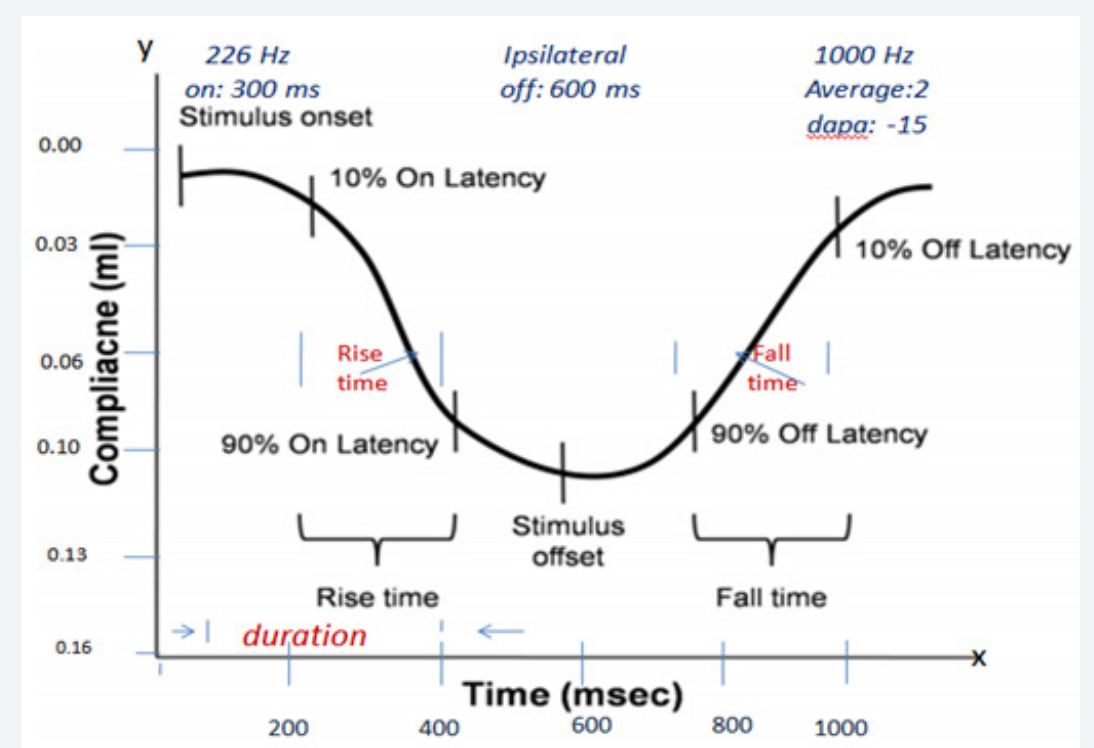

Figure 5: Waveform pattern of the acoustic reflex to illustrate the time marks for a calculation of various parameters of latency (or) Parameters of reflex latencies measured in this study.

a. The Initial Latency (L10\% - On), the time from stimulus onset to the point where the reflex response reaches $10 \%$ of its maximum amplitude, also called Onset Latency.

b. The Terminal Latency (L90\% - On), the time from stimulus onset to the point where the reflex response reaches $90 \%$ of a maximum amplitude, also called Late Latency.

c. The Initial Recovery (L90\% - off), the time from stimulus offset to the point where the reflex response decays to $90 \%$ of its maximal amplitude.

d. The Terminal Recovery (L10\% - off), the time from stimulus offset to the point where the reflex decay to $10 \%$ of maximum amplitude, also called Late Recovery.

e. Rise time: The time duration between $10 \%$ and $90 \%$ On Latencies.

f. Fall time: The time duration from $90 \%$ to $10 \%$ offset Latencies.

A. Møller (1958) reported latencies of 25 to $130 \mathrm{~ms}$ for 500 $\mathrm{Hz}$ and $1,500 \mathrm{~Hz}$ pure tones. Latencies were shorter for 1,500 $\mathrm{Hz}$ than for $500 \mathrm{~Hz}$ tones [90].

B. Dallos (1964) found a similar inverse relationship between activator intensity and reflex intensity for white noise. These findings were confirmed and expanded upon by Hung and Dallos [91] who found that AR latencies were shorter for noise signals than for pure tones, with the longest latencies for tones below $300 \mathrm{~Hz}$. The shortest latencies, on the order of $20 \mathrm{~ms}$ were in response to noise activators. The latency of the impedance change is a measure of the latency of the mechanical response of the middle ear rather than of the neural transport time for the reflex arc alone [92].
C. Zakrisson, Borg and Blom (1974) found that the electromyographic (EMG) response of the stapedius muscle in humans is as short as $12 \mathrm{~ms}$. they also reported that the EMG «threshold» is about $6 \mathrm{~dB}$ lower than that for the impedance change measured as the lowest stimulus level needed to yield $10 \%$ of the maximum response. The reported values of Onset ARL ranged from a low of $68 \mathrm{~ms}$ [93] to a high of $200 \mathrm{~ms}$ [94].

D. Jerger et al., (1986) reported that average of the onset ARL at 1,000 $\mathrm{Hz}$ and 2,000 Hz was $106 \mathrm{~ms}$. Clinically, Clemis and Sarno $[95,97]$ report the implementation of ARL as part of differential diagnosis.

E. Onset ARL is an important parameter and the other variables of ARL provide complementary information regarding the characteristic of AR pattern [88].

The literature on Acoustic Reflex Latency (ARL) will be dealt with under the following topics.

i. The effect of the time constant on Acoustic Reflex Latency

ii. The effect of stimulus parameters on Acoustic Reflex Latency

iii. The effect of temporal characteristics on Acoustic Reflex Latency

iv. Acoustic Reflex latency findings in various pathologies.

a) Conductive pathology

b) Cochlear pathology

c) Retrocochlear pathology

d) Eighth nerve tumor

e) Central auditory pathology 
f) Auditory Processing Disorder

g) Uses and applications of Acoustic Reflex Latency test (ARLT)

i. The effect of the Time constant on Acoustic Reflex Latency: The definition of ARL in terms of a percentage of maximum amplitude of the response has certain critical drawbacks. One, as mentioned by Silman and Gelfand [20] is the contamination of the rise time of the acoustic reflex by the time constant and possibly also the instrument latency of the impedance bridge. The time constant of the acoustic impedance bridge is defined as the time it takes for the impedance to change in response to an instantaneous increase in the probe tone sound-pressure level in a fixed cavity couple to an acoustic impedance bridge. The time constant also describes the shortest time period in which a given acoustic impedance bridge can track the full magnitude of the acoustic reflex response. Therefore, if the rise time of the acoustic reflex response is shorter than the time constant of the acoustic impedance bridge, then the instrument will not be able to track the time course of the acoustic reflex contraction correctly, i.e. the time constant of the instrument will be superimposed on the rise time of the acoustic reflex response. The time course for the change in amplitude of the acoustic reflex response is altered by the temporal characteristics of the measuring device.

The rationale for defining ARL in terms of the peak amplitude was that a low, signal-to noise (SIN) ratio, present at the beginning of the impedance change, obscures the acoustic reflex response at this point or that the acoustic reflex response has a slow rise time which makes it difficult to detect the beginning of the impedance change. This rationale seems to hold for measurement of ARL at the level of the ART but does not hold for measurement of the ARL at $10 \mathrm{~dB}$ SL re. ART, where the $\mathrm{S} / \mathrm{N}$ ratio is improved and the rise time is faster so that the beginning of the impedance change is sharper. The low $\mathrm{S} / \mathrm{N}$ ratio at the level of the ART can be overcome by the use of the computer averaging technique. Currently, measurement of ARL is made at suprathreshold levels (e.g $10 \mathrm{~dB}$ SL re: ART) because the $\mathrm{S} / \mathrm{N}$ ratio at ART is too poor to permit distinguishing an AR response clearly from background noise. Stimulation at suprathreshold levels produces good morphologic features of AR time course, which provides valuable information about parameters of ARL.

ii. The effect of Stimulus Parameters on Acoustic Reflex Latency

a) The rise time of the activating stimulus is correlated with stimulus intensity and directly affects the ARL, i.e. the faster the rise time, the shorter the latency [20]. Many clinics arbitrarily select a rise time between 2 and $10 \mathrm{~ms}$

b) The intensity of the activating stimulus is also correlated with ARL, i.e. the more intense the activating stimulus, the shorter the ARL $[45,65,70]$ c) During ipsilateral stimulation, intensity of $100 \mathrm{~dB}$ SPL should not be exceeded in order to avoid artifacts [40]

d) The duration of the activating stimulus does not affect the ARL directly, but a stimulus shorter than 1sec affects the ARL. Activating stimuli of $1 \mathrm{sec}$ of duration are sufficient since they give maximal temporal summation [68]

e) Early research on the acoustic reflex has shown that activating stimulus frequency affects the ART $[35,40]$. The activating frequencies of choice are 500, 1,000 and 2,000 Hz. At these frequencies, the ARL is more stable and the dispersion of the ARL values is smaller than at other activating frequencies.

f) Because of the important role of activator stimulus intensity, the detection of ART must be precise. Most instruments allow an output intensity control at intervals of $5 \mathrm{~dB}$. Nevertheless, the output intensity control should be modified if a 2 or $1 \mathrm{~dB}$ step method gives better results $[20,22,23]$

g) Overall, it is widely accepted that onset latency decreases as signal intensity increases $[3,25,26]$.

F. Ruth and Niswander (1976) reported that the rise characteristic was affected by the frequency

of the eliciting signal.

G. Rossie et al., (1985a) studied relationships between AR patterns elicited by unfiltered white noise and narrow band white noise stimuli of different duration of the same intensity. They found that latency was independent of the spectrum of the stimuli and its duration. Some investigators have shown longer ARL at high frequencies than at low frequencies [100105]. A study by Borg [2] demonstrates a longer ARL at $500 \mathrm{~Hz}$ than at 2,000 $\mathrm{Hz}$.

\section{The effect of Temporal Characteristics on Acoustic Reflex Latency}

As several investigators pointed out, interactions between temporal characteristics of acoustic-immittance instruments and morphology of recorded AR responses should be investigated [5558].

The temporal characteristics of the experimental apparatus expressed according to the terminology suggested by Lilly [26], was as follows:

a. The Initial Latency (Li), the time from signal onset to $10 \%$ of the measured steady state immittance change was $9 \mathrm{~ms}$.

b. The terminal latency (Lt), the time from signal offset to $90 \%$ of the measured steady state immittance change was 9 ms.

c. The onset time constant (Tr), the time from signal onset to $63.2 \%$ of the measured steady state immittance change was $17 \mathrm{~ms}$. 


\section{Global Journal of Otolaryngology}

d. The offset time constant (Tf), the time from signal offset to $36.8 \%$ of the measured steady state immittance change was $16 \mathrm{~ms}$.

e. The rise time (tr), the time from $10 \%$ to $90 \%$ of the measured steady state of immittance change, was $23 \mathrm{~ms}$.

f. The fall time (tf), the time from $90 \%$ to $10 \%$ of measured steady state of immittance change was $22 \mathrm{~ms}$.

g. There is remarkable agreement across studies on estimates of latency to first deviation from baseline (10\%). Actual values ranged from a low of $90 \mathrm{~ms}$ [20] to a high of 129 $\mathrm{ms}$ [30]. The present estimate of $109 \mathrm{~ms}$ is close to the average across all studies (106 ms).

\section{Acoustic Reflex Latency Findings in Various Pathologies}

a) Conductive Pathology: In ears affected by conductive pathology, the study on ARL has several limitations caused by the elevation of the ART and the pathological conditions of the effector system. In $50 \%$ of the subjects who had conductive loss of at least $30 \mathrm{~dB}$, no ART was present. Hence ARL test was difficult to do on them. In the other study done on subjects who had early unilateral otosclerosis, the ARL for contralateral stimulation at $10 \mathrm{~dB}$ SL re: ART fell within normal limits (50-110 ms). The ART values were in agreement with those reported by Terkildsen, Osterhammel and Bretlau [63].

b) Cochlear Pathology: In cochlear pathology, ARL is normal. In about $50 \%$ of ears with unilateral cochlear impairment the ARL is shorter than in the contralateral, normal-hearing ear. The shortened ARL is in agreement with the shortened latency obtained using electrocochleography [25] in cases of unilateral cochlear impairment. In a study by Clemis and Sarno [89,90], the reflex latencies for both cochlear hearing loss groups were about the same as the latencies measured for normal subjects. Using 95\% confidence limit for the normal group as normal range, $85 \%$ to $95 \%$ of the patients with cochlear hearing loss were classified as normal by Clemis and Sarno [25,27], Norris, Stelmachowicz, Bowling and Taylor [10] reported comparisons of ARL in normal and sensory neural hearing loss subjects.

Latencies were measured at 5 different points. Their results indicated that statistically significant differences existed between the normal and sensory neural groups not in onset latency, but in the measures of offset latency. These results are consistent with Norris et al., [21] study, showing lower Reflex Relaxation Index (RRI) among subjects with sensory neural disorder. Borg [23] pointed out that accurate measurements of the reflex latency are best achieved with stimuli having rise times of $10 \mathrm{~ms}$ or less. Clemis and Sarno [25] described a clinical application of ARL measurements using a commercial impedance meter modified to satisfy the stimulus parameters suggested by Borg [26] for such studies. He found the reflex latencies of the cochlear groups were shorter than those of the normal group but there were no apparent ipsi-contra differences in their sample.

\section{c) Retrocochlear Pathology}

Usually the acoustic reflex is severely altered in cases of retrocochlear pathology. The altercations include absence or elevation of the ART, acoustic reflex decay and longer than normal ARL. The absence of the ART is a very early sign and is observed in about $75 \%$ cases with hearing threshold levels of $30 \mathrm{~dB}$ HL [36-40]. Ears with retrocochlear pathology, which do not show acoustic reflex decay at $10 \mathrm{~dB}$ SL may show it at 20 dB SL re: ART [41]. The ARL is significantly increased in cases of retrocochlear pathology. This has been observed in animal experiments [45] and in experiments on humans [40-46].

The latency values for contralateral stimulation can exceed $200 \mathrm{~ms}$ and ILD (Interaural Latency Difference) in cases of retrocochlear pathology (if the lesion is unilateral). The increased ARL and TLD in cases of retrocochlear pathology are very marked and clearly discriminates between cochlear and retrocochlear pathology in more than $90 \%$ of the cases in which the ART are present bilaterally. The retrocochlear group had latencies of $181.5 \mathrm{~ms}$ and $274.0 \mathrm{~ms}$ for 1,000 and $2,000 \mathrm{~Hz}$, respectively, with no cases within the normal range. Interaural latency difference was also found to distinguish among the subject groups. The mean ILD was greater than $90 \mathrm{~ms}$ for patients with retrocochlear pathology [70].

\section{d) Eighth Nerve Tumor}

Recently, several investigators have suggested that latency of the acoustic reflex is a sensitive indicator of eighth nerve disorder. Clemis and Sarno [25] and Mangham et al., [30] evaluated latency of AR in subjects with eighth nerve tumor. They reported that onset of the AR in the ear with eighth nerve disorder was significantly delayed relative to the contralateral ear. The Interaural Latency Difference (ILD) varies depending on whether the latency measurement is made at equal reflex SLs, equal signal SPLs or equal reflex amplitudes. For both equal reflex SLs and equal signal SPLs, latency of the reflex with sound presented to the ear with eighth nerve disorder is substantially prolonged relative to latency with sound presented to the normal ear. In an investigation of reflex latency in CN VIII tumours, Jerger and Hayes (1983) reported that the reflex latencies for 500 to $2,000 \mathrm{~Hz}$ activator signals presented at $100 \mathrm{~dB}$ SPL, were two to nine times longer for the affected ear.

H. Jerger and Hayes (1983) concluded that when the acoustic reflex was measurable with the activator signal presented to an ear with a CN VIII lesion, the AR demonstrated a reduced maximum amplitude compared to the normal ear and was late with a slowly rising onset.

e) Peripheral and Central Auditory Pathology: Usually in cases of central auditory pathology, pure tone hearing threshold levels are normal, whereas the results of directional audiometry, brainstem auditory evoked potentials, and speech audiometry with synthetic sentences are impaired. Also, the ARTS are absent or elevated, and other parameters of 
the acoustic reflex (e.g. latency, magnitude) for ipsilateral or contralateral stimulation may be affected, either singly or in combination, depending upon the site and extent of the lesion. Signs of vestibular involvement are often present [20-24]. In a study conducted on subjects with Multiple Sclerosis, it was found that onset latency of crossed reflex was abnormal. Since latency is so closely related to absolute amplitude, the amplitude was evaluated in these subjects. Reduction in amplitude usually shortens the offset latency, whereas in these subjects, the offset latency was abnormally prolonged [30].

In another investigation on a subject it was illustrated that reflex amplitude measures can differentiate eighth nerve from brainstem disorder and that suprathreshold measures (e.g. latency) can be more sensitive than threshold measures. Latency measures can also be used to differentiate eighth nerve and brainstem disorder. Latency does not appear to be delayed in ears with acoustic tumor. However, both onset and offset latency can be very abnormal in brainstem disorder. Indeed, if amplitudes from two ears are equated and latency differences exist, it is quite likely sufficient evidence to rule out eighth nerve disorder.

f) Children with Auditory Processing Disorder: Different studies have demonstrated that individuals with auditory processing disorders (APD) show absence or increased acoustic reflexes, even in the presence of good ossicular-tympanic conditions. The superior olivary complex plays a common participation in the acoustic reflex and in management of auditory abilities involved in auditory processing. The acoustic reflex latency test corresponds to the time interval between the onset of the stimulus and the onset of the middle ear muscle contraction. A study was conducted to investigate the acoustic reflex latency in children without and with auditory processing disorders. The study of the latency was achieved with stimulus for $10 \mathrm{~dB}$ above the reflex threshold level ipsilateral and contralateral in frequency of 500, 1,000, 2,000 and 4,000.

A. Results: The results revealed prolongation reflex latency values in children with auditory processing disorders. It was observed prolongation contralateral reflex latency when compared with the ipsilateral results in two groups. Conclusions: The results this study reinforce the relation between the timing conduction of the pathways and auditory processing, emphasizing the importance of acoustic reflex latency results in children with auditory processing disorders.

\section{Uses and Applications of Acoustic Reflex Latency Test}

a) Acoustic reflex latency has been suggested as an indicator in otoneurological diagnosis.

b) The ARL test remains valuable as a diagnostic tool in today's audiological test battery [30]

c) Onset ARL is an important parameter, but other variables of ARL provide complementary information regarding the dynamic characteristics of AR pattern for diagnosis [25]. d) The clinical measurement of ARL, when combined with audiometric tests, may assist in differentiating between cochlear hearing impairment and central auditory disorder [710]

i. ARL test offers a simple, inexpensive method of distinguishing cochlear from retrocochlear sites of auditory disorder [9]

ii. Clemis and Sarno, and Mangham et al., encourage the use of ARL test as a sensitive and specific indicator of VIII nerve disorder.

iii. ARL gives diagnostic information about several pathological conditions of the auditory system, except in cases of conductive hearing loss in which ARL varies unpredictably.

\section{Materials \& Methods}

\section{Aim}

The purpose of the present study was to further characterize ARL in normal-hearing females between 20 and 30 years of age, to establish normative data. This would facilitate the identification of abnormal latency values in the clinical population and can be compared and hence valid for female population. This study is the first of its kind conducted at Mediclinic Al Madar. The test parameters were selected keeping in mind the applicability of the data to the clinical population to facilitate the diagnostic procedure.

\section{Sample}

The sample comprised of 30 normal-hearing females between the age range of 20 and 30 years of age who have never exhibited any middle ear pathology.

\section{Procedure: The following tests were done.}

a) Otoscopic Examination: A visual examination of ear canal and tympanic membrane of both ears using a hand-held otoscope was done to rule out presence of wax of any other foreign bodies in the ear canal. All the subjects had normal otoscopic examination.

b) Pure Tone Audiometry: Pure tone Audiometry was conducted for air conduction thresholds and bone conduction thresholds in each ear at $250 \mathrm{~Hz}, 500 \mathrm{~Hz}, 1 \mathrm{kHz}, 2 \mathrm{kHz}$, and for air conduction at $8 \mathrm{kHz}$ using Resonance Clinical Audiometer calibrated as per ANSI standards. The hearing loss criteria were based on Goodman's [35] classification. Hearing loss was defined by greater than $25 \mathrm{~dB}$ HL average for $500 \mathrm{~Hz}, 1 \mathrm{kHz}$ and $2 \mathrm{kHz}$ for each ear and or an air bone gap of greater than $10 \mathrm{~dB}$. The pure tone audiometry assessment was a manually administered individual by Hughson-Westlake procedure.

c) Tympanometry: Resonance r36m Clinical Middle Ear Analyzer was used for measuring tympanometry and the acoustic reflexes. Standard examination of aural immittance in the form of single tones $(226 \mathrm{~Hz})$ tympanometry and threshold determination for ipsilateral reflexes at $500 \mathrm{~Hz}, 1 \mathrm{kHz}, 2 \mathrm{kHz}$ and $4 \mathrm{kHz}$ were carried out. The tympanogram was classified 


\section{Global Journal of Otolaryngology}

as type ' $A$ ' which was defined as the peak pressure between + or - 50 dapa and acoustic (static) compliance between 0.2 and 1.8 $\mathrm{ml}$ following the normative values specified in the instrument manual and as per Bluestone and Klein [40]. In cases where other than type 'A' tympanogram was found, the procedure was immediately repeated to confirm the findings. Normal ART, ipsilateral was defined as consistent response of $0.03 \mathrm{ml}$ which was present at less than or equal to $95 \mathrm{~dB}$ HL for $500,1,000$, 2,000 and 4,000 Hz.

d) ARLT Assessment: Resonance r36m Clinical Middle Ear Analyzer was used for measuring tympanograms and acoustic reflexes. Ipsilateral stimuli were presented through a probe tip (226 Hz). The temporal latency of the apparatus in ARL measurement mode was specified as follows:

i. The initial latency, i.e. from signal onset to $10 \%$ of the $\mathrm{AR}$ amplitude, $<5+/-5 \mathrm{~ms}$.

ii. The terminal latency, i.e. from signal offset to $90 \%$ of amplitude, $<5+/-5 \mathrm{~ms}$.

iii. The rise time, i.e. from $10 \%$ to $90 \%$ of the AR amplitude, $<$ $30+/-5 \mathrm{~ms}$.

iv. The fall time, i.e. from $90 \%$ to $10 \%$ of the AR amplitude, $<$ $25+/-5 \mathrm{~ms}$.

The software built into the equipment compensated for a temporal delay for presentation of steady state stimulus.

\section{Procedure}

Depending on the results of the above-mentioned tests (a through c), ARLT assessment was attempted for both ears of the selected subject. The subjects were in sitting position without head or arm support. They were instructed to remain relaxed, not to move the head, nor to swallow during the recording session. ARTs were first established, using ipsilateral tonal stimulation at frequencies of 500, 1,000, 2,000 and 4,000 Hz. The ARL test was then performed in immittance component $\mathrm{Y}(\mathrm{ml})$ and a probe tone of $226 \mathrm{~Hz}$ and 85 dB SPL which supplied an adequate signal for detecting impedance change by the microphone but did not stimulate the AR. The ARL procedures were carried out using $500 \mathrm{~Hz}, 1,000,2,000$ and 4,000 $\mathrm{Hz}$ tones. To permit uniform measurements, the test stimuli were then presented at $10 \mathrm{~dB}$ above ART in $\mathrm{dB}$ HL (10 dB SL) at each tonal stimulus.

Stimulus on time or duration was set at $300 \mathrm{~ms}$ with $5 \mathrm{~ms}$ rise/ fall time. The time base was set to $1,000 \mathrm{~ms}$ and a sensitivity scale for display of waveforms was set to $-16 \mathrm{ml}$. Two recordings were averaged to improve the signal/noise ratio and thus smooth the displayed response while avoiding stapedius contraction fatigue. All measures were obtained in a quiet examination room with the subject kept still and alert. Test results were displayed in real time and on the screen along with a continuous digital read out. The temporal characteristics of the AR were expressed according to the terminology suggested by GSI (Grason-Stadler, Inc.), and the definition of all the parameters used in the present study had already been described.

\section{Results}

The results of measurement parameters of ARL are shown. The mean, standard deviation and normal range of $95 \%$ of the population of the acoustic reflex initial latency (L90\%-off) and terminal recovery (L10\%-off) obtained with various frequencies ( $500 \mathrm{~Hz}, 1,000 \mathrm{~Hz} \mathrm{2,000} \mathrm{Hz} \mathrm{and} \mathrm{4,000} \mathrm{Hz)} \mathrm{using} \mathrm{pure} \mathrm{tone} \mathrm{stimulus}$ for right and left ears are summarized in Tables $1 \& 2$. The null hypothesis was made to find out whether there is any significant difference between initial latency of right and left ears for frequencies from $500 \mathrm{~Hz}$ to $4000 \mathrm{~Hz}$. Comparison between these paired samples (right and left ears) were made and using ' $t$ '-test, the test results are obtained. Similarly, the same't'-test was applied to other parameters (terminal latency, initial recovery and terminal recovery) to find out the presence of significant difference between right and left ears for the above-mentioned frequencies.

Table 1: Summarizes Mean, Standard Deviation (SD) and $95 \%$ normal range of ipsilateral ARL upon tonal stimulation at $500 \mathrm{~Hz}$ to $4000 \mathrm{~Hz}$ for right ear. The ipsilateral onset ARL ranged from $68.9 \mathrm{~ms}$ to $149.8 \mathrm{~ms}$.

\begin{tabular}{|c|c|c|c|c|}
\hline \multirow{2}{*}{ ARL Parameters } & $500 \mathrm{~Hz}$ & $1000 \mathrm{~Hz}$ & $2000 \mathrm{~Hz}$ & $4000 \mathrm{~Hz}$ \\
\hline & Ipsilateral ARL (ms) & & & \\
\hline \multirow{2}{*}{ Mean } & 68.9 & 85.6 & 117.5 & 149.8 \\
\hline & 45.7 & 54.4 & 53.9 & 63.6 \\
\hline $\begin{array}{c}\text { SD } \\
95 \% \text { limit }\end{array}$ & $52.3-85.6$ & $66.1-105.1$ & $98.2-136.8$ & $126.6-172.9$ \\
\hline L $90 \%$ - on & 174.5 & 204.7 & 239.5 & 251.7 \\
\hline Mean & 48.6 & 40.6 & 50.3 & 28 \\
\hline $\begin{array}{c}\text { SD } \\
95 \% \text { limit }\end{array}$ & $157.1-191.9$ & $190.1-219.2$ & $221.1-257.8$ & $241.7-261.7$ \\
\hline L 10\% - off & 283.8 & 242.6 & 298.2 & 258.2 \\
\hline Mean & 52.1 & 110.4 & 106.7 & 187.7 \\
\hline 95\% limit & $255.4-312.2$ & $188.5-296.7$ & $232.0-364.3$ & $93.6-422.7$ \\
\hline
\end{tabular}




\section{Global Journal of Otolaryngology}

\begin{tabular}{c|c|c|c|c|}
\hline L 90\% - off & 104.2 & 119 & 128.5 & 113.5 \\
Mean & 73.3 & 61.2 & 50.6 & 53 \\
SD & $68.3-140.1$ & $89.9-148.1$ & $102.0-155.0$ & $61.5-165.4$ \\
\hline 95\% limit & & & \\
\hline
\end{tabular}

Table 2: summarizes the Mean, Standard Deviation (SD) and 95\%, normal range of ipsilateral ARL upon tonal stimulation at $500 \mathrm{~Hz}$ to $4000 \mathrm{~Hz}$ for left ear. Ipsilateral onset ARL for left ear ranged from 72.2 to $152.5 \mathrm{~ms}$. As shown in these tables, the initial latencies were least for low-frequency stimulation at $500 \mathrm{~Hz}$ and $1000 \mathrm{~Hz}$ and increased with stimulus frequency.

\begin{tabular}{|c|c|c|c|c|}
\hline \multirow{2}{*}{ ARL Parameters } & $500 \mathrm{~Hz}$ & $1000 \mathrm{~Hz}$ & $2000 \mathrm{~Hz}$ & $4000 \mathrm{~Hz}$ \\
\hline & Ipsilateral ARL (ms) & & & \\
\hline & 72.2 & 92.1 & 124.6 & 152.5 \\
\hline Mean & 47.6 & 58.5 & 68.1 & 68.1 \\
\hline $\begin{array}{c}\text { SD } \\
95 \% \text { limit }\end{array}$ & $54.9-89.5$ & $71.2-113.0$ & $100.2-149$ & $127.7-177.3$ \\
\hline L 90\% - on & 183.2 & 212.5 & 238.2 & 248.3 \\
\hline Mean & 48.3 & 54.9 & 44.7 & 48.9 \\
\hline $\begin{array}{c}\text { SD } \\
95 \% \text { limit }\end{array}$ & $165.9-200.5$ & $192.8-232.2$ & $222-254.5$ & $230.8-265.8$ \\
\hline L $10 \%$ - off & 302.6 & 261.6 & 276.8 & 300 \\
\hline Mean & 66.1 & 80.7 & 104.8 & 213.8 \\
\hline $\begin{array}{c}\text { SD } \\
95 \% \text { limit }\end{array}$ & $266.6-374.5$ & $222-301.1$ & $211.8-341.7$ & $112.5-487.4$ \\
\hline L 90\% - off & 102.2 & 135.4 & 131.2 & 193 \\
\hline Mean & 55.5 & 28.8 & 72.1 & 124.4 \\
\hline $95 \%$ limit & $75-129.4$ & $121.6-149.1$ & $93.5-169.0$ & $71.0-314.9$ \\
\hline
\end{tabular}

Table 3: Summarizes the " $p$ " values obtained for each parameter of ARL at various frequencies using the t-test.

\begin{tabular}{|c|c|c|c|c|}
\hline ARL Parameters & $\mathbf{5 0 0} \mathbf{~ H z}$ & $\mathbf{1 0 0 0} \mathbf{~ H z}$ & $\mathbf{2 0 0 0} \mathbf{~ H z}$ & $\mathbf{4 0 0 0} \mathbf{~ H z}$ \\
\hline $10 \%$ - on & 0.688 & 0.572 & 0.609 & 0.870 \\
\hline $90 \%$ - on & 0.412 & 0.522 & 0.919 & 0.756 \\
\hline $10 \%$ - off & 0.459 & 0.401 & 0.530 & 0.230 \\
\hline $90 \%$ - off & 0.932 & 0.254 & 0.903 & 0.285 \\
\hline
\end{tabular}

" $p$ " values obtained for ARL parameters between right and left ear using 't'-test (ipsilateral Acoustic Reflex Latency).

Table 4: This table summarizes the "p" values obtained for Interaural Latency Difference (ILD) for initial latency of $500 \mathrm{~Hz}$ with LD of $1000 \mathrm{~Hz}$, $2000 \mathrm{~Hz}$ and $4000 \mathrm{~Hz}$.

\begin{tabular}{|c|c|c|}
\hline ILD of & 'p' values & ns (not significant) \\
\hline $500 \mathrm{~Hz} \& 1,000 \mathrm{HZ}$ & 0.821 & $\mathrm{~ns}$ \\
\hline $500 \mathrm{~Hz} \& 2,000 \mathrm{HZ}$ & 0.710 & $\mathrm{~ns}$ \\
\hline $500 \mathrm{~Hz} \& 4,000 \mathrm{HZ}$ & 0.978 & $\mathrm{~ns}$ \\
\hline
\end{tabular}

not significant since $p>0.05$

"p" values obtained for ILD for initial latency of $500 \mathrm{~Hz}$ with ILD of initial latency of

other frequencies (ipsilateral Acoustic Reflex Latency)

On analyzing the test results, it has been found that the ' $p$ ' values obtained by comparing the right and left ears of any parameter for $500 \mathrm{~Hz}, 1,000 \mathrm{~Hz}, 2,000 \mathrm{~Hz}$ and 4,000 Hz shows no significant difference between them for each parameter. The same result holds true for Interaural Latency Difference (ILD) - the difference in ARL between the right and left ears of a Subject i.e. the test results indicates no significant difference between ILD for initial latency of $500 \mathrm{~Hz}$ and ILD for initial latency of $1,000 \mathrm{~Hz}, 2,000 \mathrm{~Hz}$ and 4,000 Hz. The obtained results are 'not significant', because they obtained ' $\mathrm{p}$ ' values for all the parameters at various frequencies are greater than 0.05 (i.e. $p>0.05$ ) (Tables 1-4).

\section{Discussion}

The present study done on 30 normal-hearing female subjects between the age range of 20-30 years old indicates no significant difference between the ART latency parameters of right and left ears tested from $500 \mathrm{~Hz}$ to $4,000 \mathrm{~Hz}$ and the ILD for initial latency of $500 \mathrm{~Hz}$ with ILD for initial latency of other frequencies. Similar findings were reported in the literature. Normal ARL data have been reported for limited populations with various methods of 


\section{Global Journal of Otolaryngology}

measurement including electro acoustic impedance [90-95]. The impedance method has found to be the easiest and least invasive method [100-102]. It had been found that ARL is dependent on the integrity of the auditory system from the external auditory canal to the level of the low brainstem (Annex 1).

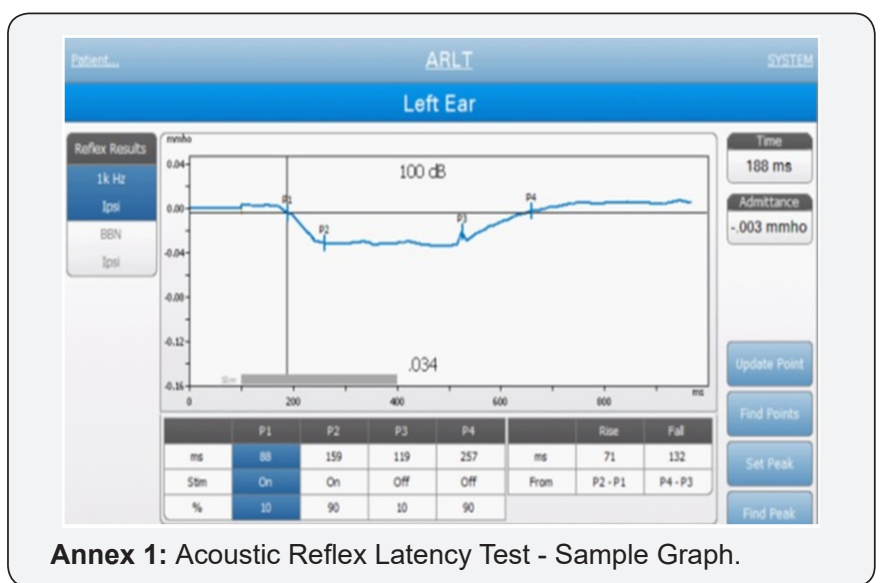

Research has shown that there is neither ear effect on ARL [89] nor sex difference in ARL [72-74]. The results of this study revealed that ARL was a stable parameter. The results of onset ARL were generally consistent with those reported by previous investigators. The reported values of onset ARL ranged from a low of $68 \mathrm{~ms}$ [74] to a high of $200 \mathrm{~ms}$ [90]. The present study conducted, shows that the onset ARL from low of $72 \mathrm{~ms}$ to high of $152 \mathrm{~ms}$. hence, the present results are in good agreement with previous findings. Fertitta and Martin [35] found a gradual increase in latency with an increase in frequency in a study conducted by them. Borg [26], comparing reflex latency produced by $500 \mathrm{~Hz}$ and 2,000 Hz pure tone signals found that the onset latency at $2,000 \mathrm{~Hz}$ was longer than the onset latency at $500 \mathrm{~Hz}$. The present study also shows remarkable agreement with previous findings.

It has been found that the important test frequencies for an evaluation of ARL are $500 \mathrm{~Hz}$ and 1,000 Hz for tonal stimuli or low band noise. In a study conducted by Clemis and Sarno [26], it was found that the mean Interaural Latency Difference (ILD) was $<25$ ms for the normal subjects. Jerger and Hayes [16] reported $78 \mathrm{~ms}$ latency for the normal ears when the measurements were made $10 \mathrm{~dB}$ above the reflex thresholds. The latency difference between the $40 \mathrm{~ms}$ reported by Jerger and Hayes [26], and the $93 \mathrm{~ms}$ to $105 \mathrm{~ms}$ latency reported by Clemis and Sarno [26] is attributable to different instrumentation and procedures. The measurement of ARL and ILD are very important. Previous investigation shows that, in normal-hearing subjects, the individual ILD for ipsilateral stimulation did not exceed $40 \mathrm{~ms}$ at any activating frequency. It also indicated that there was no interaural difference of ARL in normalhearing subjects. The present study conducted on normal-hearing female subjects supports the earlier investigations.

Stimulation at suprathreshold levels produces good morphologic features of the AR time-course, which provides valuable information about various parameters of ARL. The characteristic pattern of the AR time course, rise time and recovery time of the reflex are also related to the accuracy of ARL measurement [30-38]. Overall, it is widely accepted that onset latency decreases as signal intensity increases [24-30]. Ruth and Niswander [15] reported that ARL decreases as stimulus intensity increases for the stimuli of 500 and 1,000 $\mathrm{Hz}$ pure tone and wide-band noise stimuli. Some Investigations have shown longer ARL at high frequencies than at low frequencies [33-36]. A study by Borg [25] demonstrated a longer ARL at $500 \mathrm{~Hz}$ than at 2,000 Hz. Resonance r36m Clinical Middle Ear Analyzer has a system which allows one to measure automatically the $10 \%$ endpoint of the latency on the curve as initial latency and the $90 \%$ endpoint of the latency on the curve as terminal latency, some arbitrary definition and subjective analysis of data of ARL may be avoided.

The discrepancy among investigators may be due to the difference between the definitions of ARL ad instrumentation used in their studies. However, the results of this study indicate that when the samples were compared using ' $t$ '-test, the values obtained were found to be greater than 0.05 (i.e. > 0.05), which is a sign of 'not significant' difference among the ARL parameters. The data obtained in this study is normative data for the mentioned age and such findings may be clinically important, since a significant interaural difference of ARL may provide diagnostic information. Thus, the entire null hypothesis proposed in this study is accepted.

\section{Limitations of the Study}

There are numerous instrumentation factors that must be considered for the accurate measurement of latency and rise time. Response time characteristics of immittance instruments can adversely affect measurement of suprathreshold temporal aspects of the reflex. The temporal characteristic of the measurement apparatus may influence the apparent morphology of the reflex at low frequencies. Hence, due to this reason, each laboratory should use normative data for specific equipment in determining Acoustic Reflex Latency. Since few published reports exist regarding the test-retest reliability of ARL of normal values in children and aging subjects, establishment of test-retest reliability normal ARL should also be further investigated. Apart from ARLT, there are many other audiological test procedures, which are more reliable and have gained recognition in clinical audiology. Though ARLT can be used for the diagnosis of cochlear from retrocochlear disorder, it is important to note that no recent research or clinical study have been done on further investigation of ARL in the past few years, most likely due to above mentioned factors.

\section{Conclusion}

The present study was done on 30 normal-hearing female subjects between the age range of 20 and 30 years. Audiometry and impedance testing (Tympanometry and ART) was done to find out normal hearing sensitivity and to rule out any middle ear pathology. ARTs were found to be < or equal to $95 \mathrm{~dB}$ HL for all the subjects pathology and ARLT was done by presenting $10 \mathrm{~dB}$ above the reflex threshold. The values for different parameters of ARL from $500 \mathrm{~Hz}$ to $4,000 \mathrm{~Hz}$ were obtained using Resonance r36m Clinical Middle Ear Analyzer, and it was found that there is no significant difference 


\section{Global Journal of Otolaryngology}

between right and left ears for any parameter at all frequencies. No significant difference has been found between ILD for initial latency of $500 \mathrm{~Hz}$ with ILD for initial latency of other frequencies.

The temporal characteristics have a profound effect upon aural acoustic - immittance measurements for determination of acoustic reflex latency. ARL has been suggested as an indicator in otoneurological diagnosis. The measurement of ARL is very important in cases of retrocochlear pathology and it gives diagnostic information about several pathological conditions of the auditory system. The available literature says that Onset ARL is an important parameter, but other variables of ARL provide complementary information regarding the dynamic characteristics of AR pattern. Previous investigations revealed that ARL was a stable parameter, especially with 500 and $1,000 \mathrm{~Hz}$ tonal stimuli and onset latency decreases as stimulus frequency increases.

The use of the electro-acoustic impedance bridge together with an averaging computer offers great potential in the study of ARL. Significant interaural difference of ARL may provide diagnostic information. To conclude, the clinical measurement of ARL, when combined with audiometric tests, may assist in differentiating between cochlear hearing impairment and central auditory disorder. The present results might have important implication for the future research on ARL in patients with various cochlear and retrocochlear lesions as a part of differential diagnosis. This makes ARL test as a valuable diagnostic tool in today's audiological test battery. An attempt has been made to develop indigenous data in the present study and it is hoped that this data will form more representative values for further research.

\section{References}

1. Alberti PW, Fria TJ, Cummings F (1977) The clinical utility of ipsilatera stapedial reflexes tests. Journal of Otolaryngology 6: 466-472. In Green KW, Margolis RH (1984) The ipsilateral acoustic reflex. In Silman, S (1984). The Acoustic Reflex Basic Principles and Clinical Applications FL: Academic Press, Inc. Orlando, USA, 275-296.

2. Alberti, PWR, Kristensen R, (1970) The clinical application of impedance audiometry. Laryngoscope, 80: 735-746. In Gelfand, SA (1984) The contralateral acoustic reflex threshold. In Silman S (1984) The contralateral acoustic reflex threshold. In Silman S (1984) The Acoustic Reflex Basic Principles and Clinical Applications FL: Academic Press, Inc. Orlando, USA, 137-180.

3. Alford B, Jerger JF, Coats A, Peterson C, Weber S (1973) Neurophysiology of facial nerve testing. In Northern Jl, Gabbard SA (Eds.), The acoustic reflex measurements. Handbook of Clinical Audiology, (4 ${ }^{\text {th }}$ edn), Williams and Wilkins, Baltimore, USA.

4. (1982) American National Standards Institute (ANSI). American National Standard specifications for aural acoustic immittance instruments. In Lilly DJ (1984) Evaluation of the response time of acoustic immittance instruments. In Silman S (1984) The Acoustic Reflex Basic Principles and Clinical Applications FL: Academic Press, Orlando, New York, 101-103.

5. Linares AE, Mota CR (2004) Acoustic reflex latency in children with auditory processing alteration. International Archives of Otorhinolaryngology 8(1).

6. Anderson H, Barr B (1966) Conductive recruitment. Acta Otolaryngologica 62(6): 171-184. In Gelfand SA (1984) The contralateral acoustic reflex threshold. In Silman S (1984) The Acoustic
Reflex Basic Principles and Clinical Applications FL: Academic Press, Orlando, New York, USA, 137-180.

7. Beedle, RK, Harford ER (1973) A comparison of acoustic reflex and loudness growth in normal and pathological ears. Journal of Speech and Hearing Research 16: 271-281. In Gelfand SA (1984) The Acoustic Reflex Basic Principles and Clinical Applications FL: Academic Press, Orlando, New York, USA, 137-180.

8. Bess, FH, McConnell FE (1981) Audiology and education and the hearing impaired child, CV Mosby Company: St Louis, USA

9. Bluestone, CD, Klein JO (1995) Otitis media in infants and children. WB Saunders Company, Philadelphia, USA.

10. Borg E (1972) On the use of acoustic middle ear muscle reflexes in studies of auditory functions in non-anaesthetized rabbits. Acta Otolaryngolica 74: 163-171. In Bosatra A, Russolo M, Silverman CA (1984) Acoustic Reflex Latency: State of the Art. In Silman S (1984) The acoustic reflex: basic principles and clinical applications FL: Academic Press, Orlando, New York, USA, 301-325.

11. Borg E (1973) On the neuronal organization of the acoustic middle ear reflex. A physiological and anatomical study. Brain Res 49: 101-123. In Qiu W, Stucker F (1998) Characterization of acoustic reflex latency in normal hearing subjects. Scandinavian Audiology 27(1): 43-49.

12. Borg E (1976) Dynamic characteristics of the intra-aural muscle reflex. In Fieldman AS, Wilber LA (Eds.) Acoustic impedance and admittance - the measurement of middle ear function Baltimore: Williams and Wilkins (236-299). In Gelfand SA (1998) Hearing: an introduction to psychological and physiological acoustics ( $3^{\text {rd }}$ edition), Marcel Dekker, Inc, New York, USA, 83-114.

13. Borg E (1992) Time course of the human acoustic stapedius reflex. Scandinavian Audiology 11: 237-242. In Qiu W, Stucker F (1998) Characterization of acoustic reflex latency in normal hearing subjects. Scandinavian Audiology 27 (1): 43-49.

14. Bosatra A, Russolo M, Silverman CA (1984) Acoustic Reflex Latency: State of the ARLT. In Silman S The Acoustic Reflex New York: academic Press, 301-320. In Qiu W, Stucker,F (1998) Characterization of acoustic reflex latency in normal hearing subjects. Scandinavian Audiology 27 (1): 43-49.

15. Brask T (1978) Extratympanic manometry in man. Scandinavian Audiology. In Green KW, Margolis RH (1984) The ipsilateral acoustic reflex. In Silman S (1984) The Acoustic Reflex: Basic Principles and Clinical Applications FL: Academic Press, Orlando, New York, USA, 275-296.

16. Charles A Mangham, Patricia A Burnett, Roger C Lindeman (1982) Standardization of Acoustic Reflex Latency.

17. Chiveralls K (1977) A further examination of the use of the stapedius reflex in diagnosis of acoustic neuroma. Audiology 16: 331-337. In Gelfand SA (1984) The contralateral acoustic reflex threshold. In Silman S (1984) The Acoustic Reflex: Basic Principles and Clinical Applications FL: Academic Press, Orlando, New York, USA, 137-180.

18. Chiveralls K, FitzSimons R (1973) Stapedial reflex action in normal subjects. British Journal of Audiology 7: 105-110. In Gelfand SA (1984) The contralateral acoustic reflex threshold. In Silman S (1984) The Acoustic Reflex: Basic Principles and Clinical Applications FL: Academic Press, Orlando, New York, USA, 137-180.

19. Chiverals K, FitzSimons R, Beck GB, Kernohan H (1976) The diagnostic significance of the stapedius reflex. British Journal of Audiology 10: 122-128. In Gelfand SA (1984) The contralateral acoustic reflex threshold. In Silman S (1984) The Acoustic Reflex: Basic Principles and Clinical Applications FL: Academic Press, Orlando, New York, USA, 137-180.

20. Church GT, Cudahy EA (1984) The time course of the acoustic reflex, Ear Hear 5: 235-242. In Qiu W, Stucker F (1998) Characterization 


\section{Global Journal of Otolaryngology}

of acoustic reflex latency in normal hearing subjects. Scandinavian Audiology 27(1): 43-49.

21. Citron D, Adour K (1978) Acoustic reflex and loudness discomfort in acute facial paralysis. Arch Otolaryngol 104: 303-308. In Northern JL, Gabbard SA (1994) The acoustic reflex measurements. In Katz J (1994) Handbook of Clinical Audiology ( $4^{\text {th }}$ ed), Baltimore: Williams and Wilkins, USA, 300-314.

22. Clemis JD, Sarno CN (1979) Acoustic stapedial reflex latency versus BERA wave I latency in the detection of eighth nerve lesions. Journal of Acoustic Society of America 66(34).

23. Clemis JD, Sarno CN (1979) Acoustic stapedial reflex latency versus BERA wave I latency in the detection of eighth nerve lesions. Journal of Acoustic Society of America 66(34).

24. Clemis JD, Sarno C.N (1980) The Acoustic Reflex Latency Test: Clinical Application. Laryngoscope 90: 601-611. In Stach B, Jerger J (1991) Immittance Measures in Auditory Disorders. In Jacobson J, Northern (1991) Diagnostic Audiology, TX: Pro-Ed, Austin, 113-138.

25. Clemis JD, Sarno CN (1980) Acoustic reflex latency test in the evaluation of nontumor patients with abnormal brainstem latencies. Annals of Otology, Rhinology and Laryngology 89: 296-302. In Wilson RH, Margolis RH (1991) Acoustic reflex measurements. In Rintelmann WF (1991) Hearing Assessment ( $2^{\text {nd }}$ ed), Allyn and Bacon 247-310.

26. Colletti V (1975) Stapedius reflex abnormalities in multiple sclerosis. Audiology 114: 63-70. In Hannley M (1984) Immittance Audiometry. In Jerger J (1984) Hearing disorders in adults California: College Hill Press, California, 56-79.

27. Creten WL, Vanpeperstraete PM, Vancamp KJ, Doclo JR (1976) An experimental study on diphasic acoustic patterns in normal ears. Scandinavian Audiology 5: 3-8. In Lilly DJ (1984) Evaluation of the response time of acoustic immittance instruments. In Silman S (1984) The Acoustic Reflex: Basic Principles and Clinical Applications FL: Academic Press, Orlando, New York, USA, 101-113.

28. Dallos P (1964) Dynamics of the acoustic reflex: Phenomenological aspects. Journal of Acoustical Society of America 36: 2175-2183. In Gelfand SA (1998) Hearing: An introduction to psychological and physiological acoustics ( $3^{\text {rd }}$ ed), New York: Marcel Dekker Inc, New York, USA, 83-113.

29. Djupesland G, Zwislocki J (1971) Effect of temporal summation on the human stapedius reflex. Acta Oto-Laryngologica 71: 262-265. In Bosatra A, Russolo M, Silverman CA (1984) Acoustic reflex Latency: State of the Art. In Silman S (1984) The Acoustic Reflex: Basic Principles and Clinical Applications Orlando, FL: Academic Press Inc, New York, USA, 301-325.

30. Fertitta S, Martin FN (1973) The latent period of the intra aural muscle reflex in normal and pathological ears. J Aud Res 13: 157-161. In Qiu W, Stucker F (1998) Characterization of Acoustic Reflex Latency in normal hearing subjects. Scandinavian Audiology 27(1): 43-49.

31. Gelfand SA, Piper N (1981) Acoustic reflex thresholds in young and elderly subjects with normal hearing. Journal of the Acoustical Society of America 69: 295-297.

32. Gellfand SA, Silman S (1982) Acoustic reflex thresholds in brain damaged patients. Ear and Hearing 3: 93-95.

33. Gelfand SA, Piper N, Silman S (1983) Effects of hearing levels at the activator and other frequencies upon the expected levels of the acoustic reflex threshold. Journal of Speech and Hearing Disorders 48 11-17. In Gelfand SA (1984) The Acoustic Reflex: Basic Principles and Clinical Applications FL: Academic Press, Inc, Orlando, New York, USA (137-180).

34. Gorga MP, Stelmachowicz PG (1983) Temporal characteristics of the acoustic reflex. Audiology 22: 120-127. In Qiu W, Stucker F (1998) Characaterization of acoustic reflex latency in normal hearing subjects. Scandinavian Audiology 27(1): 43-49.
35. Green KW, Margolis RH (1984) The ipsilateral acoustic reflex. In Silman S (1984) The Acoustic Reflex: Basic Principles and Clinical Applications FL: Academic Press, Inc, Orlando, New York, USA, 275-296.

36. Hall JW (1978) Predicting hearing level from the acoustic reflexes: a comparison of three methods. Arch Otolaryngol 104: 601-606. In Northern JL, Gabbard SA (1994) The acoustic reflex. In Katz J (1994) Handbook of clinical audiology (4 ${ }^{\text {th }}$ ed), 300-314.

37. Hall JW, Weaver T (1979) Impedance audiometry in a young population the effect of age, sex and tympanogram abnormalities. J-Otolaryngol 3: 210-221. In Northern JL Gabbard SA (1994) The acoustic reflex measurements. In Katz J (1994) Handbook of Clinical Audiology (4 $4^{\text {th }}$ ed), Baltimore: Williams and Wilkins, USA, 300-314.

38. Handler SD, Margolis RH (1977) Predicting hearing loss from stapedial reflex thresholds in patients with sensorineural impairment. Annals of otology, Rhinology and Laryngology 84: 423-431. In Gelfand SA (1984) The contralateral acoustic reflex threshold. In Silman S (1984) The Acoustic Reflex: Basic Principles and Clinical Applications FL: Academic Press, Inc, Orlando, New York, USA, 137-180.

39. Hess K (1979) Stapedius reflex in multiple sclerosis. J Neural Neurosurg Psychiatry 342:331. In Jerger J, Oliver TA, Stach B (1986) Problems in the clinical measurement of acoustic reflex latency. Scandinavian Audiology 15(1): 31-40

40. Holmes DW, Woodford CM (1977) Acoustic reflex threshold and loudness discomfort level: relationships in children with profound hearing losses. Journal of the American Audiological Society 2: 193 196. In Gelfand SA (1984) The Acoustic Reflex: Basic Principles and Clinical Applications Orlando, FL: Academic Press, Inc, New York, USA, 137-180.

41. Hung I, Dallos P (1972) Study of the acoustic reflex in human being: I Dynamic Characteristics. J Acoust Soc Amer 52: 1168-1180. In Gelfand SA (1998) Hearing: An introduction to psychological and physiological acoustics ( $3^{\text {rd }}$ ed), New York: Marcel Dekker, Inc, New York, USA, 83113.

42. Jepsen O (1963) Middle ear muscle reflexes in man. In Jerger J Modern developments in audiology, New York: Academic Press, Inc, 193-239. In Gelfand SA (1984) The contralateral acoustic reflex threshold. In Silman S (1984) The Acoustic Reflex: Basic Principles and Clinical Applications FL: Academic Press, Inc, Orlando, New York, USA, 137 180.

43. Jerger J (1970) Clinical experience with impedance audiometry. Archives of Otolaryngology 92: 311-324. In Gelfand SA (1984) The contralateral acoustic reflex threshold. In Silman S (1984) The Acoustic Reflex: Basic Principles and Clinical Applications FL: Academic Press, Inc, Orlando, New York, USA, (275-296).

44. Jerger J (1975) Diagnostic use of impedance measures. In Jerger $H$ (1990) Handbook of clinical impedance audiometry. American Electromedics corporation. In Nagaraja MN (1990) Testing interpreting and recording procedures. In Basavaraj V, Kacker SK Indian Speech and Hearing Tests - The ISHA Battery, (Ed.), 109-126.

45. Jerger J, Harford E, Clemis J, Alford B (1974) The acoustic reflex in eighth nerve disorders. Archives of Otolaryngology 99: 409-413. In Bosatra A, Russolo M, Silverman CA (1984) Acoustic Reflex Latency: State of the Art. In Silman S The Acoustic Reflex: Basic Principles and Clinical Applications FL: Academic Press, Inc, Orlando, New York, USA, 301-325.

46. Jerger J, Hayes D (1983) Latency of the acoustic reflex in eighth nerve tumor. Arch Otolaryngol 109(1): 1-5. In Qiu W, Stucker F (1998) Characterization of acoustic reflex latency in normal hearing subjects. Scandinavian Audiology 27 (1): 43-49.

47. Jerger J S, Mauldin L (1972) Studies in impedance audiometry: I Normal and Sensorineural ears. Archives of Otolaryngology 96: 513523. In Gelfand SA (1984) The contralateral acoustic reflex threshold. In Silman S (1984) The Acoustic Reflex: Basic Principles and Clinical 


\section{Global Journal of Otolaryngology}

Applications FL: Academic Press, Inc, Orlando, New York, USA, 137180.

48. Jerger J, Oliver TA, Stach B (1986) Problems in clinical measurement of acoustic reflex latency. Scandinavian Audiology 15(1): 31-40. In Qiu W, Stucker F (1998) Characterization of acoustic reflex latency in normal hearing subjects. Scandinavian Audiology 27(1): 43-49.

49. Jerger JF, Oliver TA, Chimel RA (1988) Prediction of dynamic range from stapedius reflex in cochlear implant patients. Ear Hear 9: 4-8. In Northern JL, Gabbard SA (1994) The acoustic reflex measurements. In Katz J (1994) Handbook of clinical audiology, ( $4^{\text {th }}$ ed), Baltimore: Williams and Wilkins, USA, (300-314).

50. Jerger S, Jerger J (1977) Diagnostic value of crossed and uncrossed acoustic reflexes. Archives of Otolaryngology 103: 445-453. In Green KW, Margolis RH (1984) The ipsilateral acoustic reflex. In Silman S (1984) The Acoustic Reflex: Basic Principles and Clinical Applications FL: Academic Press, Inc, Orlando, New York, USA, 275-296.

51. Keith R (1977) An evaluation of predicting hearing loss from the acoustic reflex. Archives of Otolaryngology 103: 419-424. In Gelfand SA (1984) The contralateral acoustic reflex threshold. In Silma S (1984) The Acoustic Reflex: Basic Principles and Clinical Applications FL: Academic Press, Inc, Orlando, New York, USA, (137-180).

52. KlockhoffI (1961) Middle ear muscle reflexes in man. In Gelfand SA (1984) The contralateral acoustic reflex threshold. In Silman S (1984) The Acoustic Reflex: Basic Principles and Clinical Applications. FL: Academic Press, Inc, Acta Otolaryngologica, Orlando, USA, Suppl. 154: 137-180.

53. Kunov $H$ (1977) The eardrum artifact in ipsilateral reflex measurements. In Green KW Margolis RH (1984) The ipsilateral acoustic reflex. In Silman S (1984) The Acoustic Reflex: Basic Principles and Clinical Applications FL: Academic Press, Inc, Scandinavian Audiology, Orlando, USA, 6: 163-166, 275-296.

54. Liden G, Nilsson E, Laaskinen O, Roof BF, Miller J (1974) The stapedia reflex and motor retraction time: a parallel investigation of the effect of the drugs. Scandinavian Audiology 3: 73-80. In Qiu W, Stucker F (1998) Characterization of acoustic reflex latency in normal hearing subjects. Scandinavian Audiology 27 (1): 43-49.

55. Lilly DJ (1964) Some properties of acoustic reflex in man. Journal of the Acoustical society of America 36 (2007) In Bosatra A, Russolo M, Silverman cA (1984) Acoustic Reflex Latency: State of the Art. In Silman S (1984) the Acoustic Reflex: Basic Principles and Clinica Applications, Academic Press, Inc., Orlando, Florida, USA, 301-325.

56. Lilly DJ (1972) Acoustic impedance at the tympanic membrane. In Katz J (edn.). Handbook of Clinical Audiology ( $1^{\text {st }}$ edn.). Baltimore: Williams and Wilkins. In Nagaraja MN (1990) Testing interpreting and recording procedures. In Basavaraj V, Kacker SK (1990) Indian Speech Language and Hearing Tests, The ISHA Battery.

57. Lilly DJ (1984) Evaluation of the response time of the acoustic immittance instruments. In Silman S (1984) the Acoustic Reflex. In Qiu W, Stucker F (1998) Characterization of acoustic reflex latency in normal hearing subjects. Scandinavian Audiology 27(1): 43-49.

58. Lutman ME, Leis BR (1980) Ipsilateral acoustic reflex artifacts measured in cadavers. Scandinavian Audiology 9: 33-39. In Green KW, Margolis RH (1984) the ipsilateral acoustic reflex. In Silman S (1984) The Acoustic Reflex: Basic Principles and Clinical Applications Academic Press, Inc., Orlando, Florida, USA, 275-296.

59. Lutman NE, Leis BR (1980) Ipsilateral acoustic reflex artifacts measured in cadavers. Scandinavian Audiology 9: 33-39. Bosatra A, Russolo M, Silverman CA (1984) Acoustic Reflex Latency: State of the Art. In Silman S (1984) The Acoustic Reflex: Basic Principles and Clinical Applications, Academic Press, Inc., Orlando, Florida, USA, 301325
60. Mangham C, Lindeman E (1980) The negative acoustic reflex in retro cochlear disorders. Laryngoscope 90: 1753-1761. In Hannley M (1984) Immittance audiometry. In Jerger J (1984) Hearing disorders in adults. College Hill Press, California, USA, 56-79.

61. Mangham CA, Lindeman RC (1981) The negative acoustic reflex in retro cochlear disorders. Laryngoscope 90: 1753-1761. In Bosatra A, Russolo M, Silverman CA (1984) Acoustic Reflex Latency: State of the Art. In Silman S (1984) The Acoustic Reflex: Basic Principles and Clinical Applications, Academic Press, Inc., Orlando, Florida, USA, 310325.

62. Mangham CA, Miller JM (1979) A case for further quantification of the stapedius reflex. Archives of Otolaryngology 105: 595-596. CA, Lindeman, RC (1980).

63. Mangham CA, Burnett PA, Lindeman RC (1982) Standardization of acoustic reflex latency: a study of humans and nonhumans primates. Annals of Otology, Rhinology and Laryngology 91: 169-174. In Lilly DJ (1984) Evaluation of the response time of acoustic immittance instruments. In Silman S (1984) The Acoustic Reflex: Basic Principles and Clinical Applications, Academic Press, Inc., Orlando, Florida, USA, 101-133.

64. Mangham CA, Burnett PA, Lindeman RC (1983) Standardization of acoustic reflex latency: A study of humans and nonhumans primates. Ann Otol Rhinol Laryngol 91: 169-174. In Qiu W, Stucker F (1998) Characterization of acoustic reflex latency in normal hearing subjects. Scandinavian Audiology 27(1): 43-49.

65. Mangham CA, Lindeman RC, Dawson WR (1980) Stapedius reflex quantification in acoustic tumor patients. Laryngoscope 90: 242-250. In Gelfand SA (1984) The contralateral acoustic reflex threshold. In Silman S (1984) The Acoustic Reflex: Basic Principles and Clinical Applications, Academic Press, Inc., Orlando, Florida, USA, 137-180.

66. Mangham CA, Lindeman RC, Dawson WR (1980) Stapedius reflex quantification in acoustic tumor patients. Laryngoscope 90: 242250. In Bosatra A, Russolo M, Silverman CA (1984) Acoustic reflex latency: State of the Art. In Silman S (1984) The Acoustic Reflex: Basic Principles and Clinical Applications, Academic Press, Inc., Orlando, Florida, USA, 301-325.

67. Margolis RH, Fox CM (1977) A comparison of three methods for predicting big loss from ARTs. Journal of Speech and Hearing Research 20: 241-253. In Gelfand SA (1984) The contralateral acoustic reflex threshold. In Silman S (1984) The Acoustic Reflex: Basic Principles and Clinical Applications, Academic Press, Inc., Orlando, Florida, USA, 137180 .

68. McPherson DL, Thompson D (1977) Quantification of the threshold and latency parameters of the acoustic reflex in humans. Acta Otolaryngol (Stockh) 90 (suppl 353) In Qiu W, Stucker F (1998) Characterization of acoustic reflex latency in normal hearing subjects. Scandinavian Audiology 27(1): 43-49.

69. Metz O (1946) The acoustic impedance measured on normal and pathological ears. Acta Otolaryngologica 39: 397-405. In Gelfand SA (1998) Hearing: An Introduction to psychological and physiological acoustics ( $3^{\text {rd }}$ edn.). New York, USA, 83-114.

70. Metz 0 (1952) Threshold of reflex contractions of muscles of middle ear and recruitment of loudness. Archives of Otolaryngology 55: 536543. In Gelfand SA (1984) The contralateral acoustic reflex threshold. In Silman S (1984) The Acoustic Reflex: Basic Principles and Clinical Applications, Academic Press, Inc., Orlando, Florida, USA, 137-180.

71. Moller A (1962) The sensitivity of contraction of tympanic muscle in man. Annals of Otology, Rhinology, Laryngology 71: 86-95.

72. Moller AR (1958) Intra-aural muscles contraction in man, examined by measuring acoustic impedance of the ear. The Laryngoscope 68: 48-62. In Gelfand SA (1998) Hearing: An introduction to psychological and 


\section{Global Journal of Otolaryngology}

physiological acoustics. ( $3^{\text {rd }}$ edn.). Inc., New York, USA, 83-114.

73. Moller AR (1961) Bilateral contraction of the tympanic muscles in man. Annals of Otology, Rhinology, Laryngology 70: 735-752. In Green KW, Margolis RH (1984) The ipsilateral acoustic reflex. In Silman S (1984) The Acoustic Reflex: Basic Principles and Clinical Applications, Academic Press, Inc., Orlando, Florida, USA, 275-296.

74. Moller AR (1962a) The sensitivity of contraction of tympanic muscle in man. Annals of Otology, Rhinology, Laryngology, 71: 86-95. In Green KW, Margolis RH (1984) The ipsilateral acoustic reflex. In Silman S (1984) The Acoustic Reflex: Basic Principles and Clinical Applications, Academic Press, Inc., Orlando, Florida, USA, 275-296

75. Moller AR (1962b) Acoustic reflex in man. Journal of the Acoustical Society of America 34: 1524-1534. In Green KW, Margolis RH (1984) The ipsilateral acoustic reflex. In Silman S (1984) The acoustic reflex: basic principles and clinical applications, Academic Press, Orlando, FL, USA, 275-296. Annals of Otology, Rhinology, Laryngology 70: 735752. In Green KW, Margolis RH (1984) The ipsilateral acoustic reflex. In Silman S (1984) The Acoustic Reflex: Basic Principles and Clinica Applications, Academic Press, Inc., Orlando, Florida, USA, 275-296

76. Moller Aa (1958) Inter aural muscle contraction in man examined by measuring acoustic impedance of the ear. Laryngoscope 68: 48-62. In Hannley M (1984) Immittance Audiometry. In Jerger J (1984) Hearing disorders in adults, College Hill Press, California, USA, 56-79.

77. Neergaard EB, Rasmussen PE (1966) Latency of the stapedius muscle reflex in man. Arch Orolaryngol 84: 173-80. In Qiu W, Stucker F (1998) Characterization of acoustic reflex latency in normal hearing subjects. Scandinavian Audiology 27(1): 43-49.

78. Norris T, Stelmachowicz P, Taylor O (1974) Acoustic reflex relaxation to identify sensorineural hearing impairment. Archives of Otolaryngology 99: 194-197. In Hannley M (1984) Immittance audiometry. In Jerger (1984) Hearing disorders in adults. College Hill Press, California, USA 56-79.

79. Norris TW, Stelmachowicz P, Bowling C, Taylor D (1974) Latency measures of the acoustic reflex: Normal versus Sensorineural Audiology 13: 464. In Jerger J, Oliver TA, Stach B (1986) Problems in the clinical measurement of acoustic reflex latency. Scandinavian Audiology 15(1): 31-40.

80. Olsen WO (1991) Special Auditory Tests: A historical perspective. In Jacobson J, Northern J (1991) Diagnostic Audiology (19-52) Austin TX: Pro-Ed. In Northern JL, Gabbard SA (1994) The acoustic reflex measurements. In Katz J (1994) Handbook of clinical audiology. ( $4^{\text {th }}$ edn.). Williams and Wilkins, Baltimore, USA, 300-314.

81. Perlman HB, Case TJ (1939) Latent period of the crosses stapedius reflex in man. Ann Otol Rhinol Laryngol 48: 663-675. In Qiu W, Stucker F (1998) Characterization of acoustic reflex latency in normal hearing subjects. Scandinavian Audiology 27(1): 43-49.

82. Peterson JL, Liden G (1972) Some static characteristics of the stapedial muscle reflex. Audiology 11: 97-114. In Gelfand SA (1984) The contralateral acoustic reflex threshold. In Silman S (1984) The Acoustic Reflex: Basic Principles and Clinical Applications, Academic Press, Inc., Orlando, Florida, USA, 137-180.

83. Popelka G, Dubno J (1978) Comments on the acoustic reflex response for bone conducted signals. Acta Oto-Laryngologica (Stockholm) 86: 64-70. In Shanks JE (1987) Aural acoustic immittance standards. Seminars in Hearing 8(4): 307-317.

84. Popelka GR (1981) Hearing assessment with the acoustic reflex. (edn). Grune and Stratton, New York, USA. In Gelfand SA (1984) The contralateral acoustic reflex threshold. In Silman S (1984) The Acoustic Reflex: Basic Principles and Clinical Applications, Academic Press, Inc., Orlando, Florida, USA, 137-180.

85. Popelka GR, Margolis RH, Wiley TL (1976) Effect of activating signal bandwidth in acoustic reflex thresholds. Journal of the Acoustical
Society of America 59: 153-159. In Gelfand SA (1984) The contralateral acoustic reflex threshold. In Silman S (1984) The Acoustic Reflex: Basic Principles and Clinical Applications, Academic Press, Inc., Orlando, Florida, USA, 137-180.

86. Prabhu P, Divyashree KN, Neeraja R, Akhilandeshwari S (2015) Effect of Contralateral Noise on Acoustic Reflex Latency Measures. J Int Adv Otol 11(3): 243-247.

87. Ritter R, Johnson RM, Northern JL (1979) The controversial relationship between loudness discomfort levels and acoustic reflex thresholds. Journal of the American Auditory Society 4: 123-131. In Gelfand SA (1984) The contralateral acoustic reflex threshold. In Silman S (1984) The Acoustic Reflex: Basic Principles and Clinical Applications, Academic Press, Inc., Orlando, Florida, USA, 137-180.

88. Rossi G, Solero P, Rolando M (1985a) Relationships between acoustic reflex patterns elicited by unfiltered white noise and narrow band noise stimuli of different duration but of the same intensity. J Laryngol Otol 99: 857-863. In Qiu W, Stucker F (1998) Characterization of acoustic reflex latency in normal hearing subjects. Scandinavian Audiology 21(1): 43-49.

89. Rossi G, Solero P, Rolando M (1985b) Influence of stimulus duration and intensity on acoustic reflex parameters. Acta Otolaryngol (Stockh) 99: 348-352. In Qiu W, Stucker F (1998) Characterization of acoustic reflex latency in normal hearing subjects. Scandinavian Audiology 27(1): 43-49.

90. Ruth RA, Niswander PS (1976) Acoustic reflex latency as a function of frequency and intensity of eliciting stimulus. J Am Audiol Soc 2: 54-60. In Qiu W, Stacker F (1998) Characterization of acoustic reflex latency in normal hearing subjects. Scandinavian Audiology 27(1): 43-49.

91. Sellari Franceschini S, Bruschini P, Pardini L, Berrettini S (1986) Quantification of paramaetrs of the acoustic reflex in normal ears. Audiology 25: 165-175. In Qiu W, Stucker F (1998) Characterization of acoustic reflex latency in normal hearing subjects 27(1): 43-49.

92. Silman S, Gelfand SA (1979) Prediction of hearing levels from reflex thresholds in persons with high-frequency hearing losses. Journal of Speech and Hearing 22: 697-707. In Gelfand SA (1984) The contralateral acoustic reflex threshold. In Silman S (1984) The Acoustic Reflex: Basic Principles and Clinical Applications, Academic Press, Inc., Orlando, Florida, USA, 137-180.

93. Silman S, Gelfand SA (1981a) The relationship between magnitude of hearing loss and acoustic reflex threshold levels. Journal of Speech and Hearing disorders 46: 312-316. In Gelfand SA (1984) The contralateral acoustic reflex threshold. In Silman S (1984) The Acoustic Reflex: Basic Principles and Clinical Applications, Academic Press, Inc., Orlando, Florida, USA, 137-180.

94. Silman S, Gelfand SA (1982) The acoustic reflex in diagnostic audiology Part 2 Audiology 7: 125-138. In Bosatra A, Russolo M, Silverman CA (1984) Acoustic Reflex Latency: State of the Art. In Silman S (1984) The Acoustic Reflex: Basic Principles and Clinical Applications, Academic Press, Inc., Orlando, Florida, USA, 310-325.

95. Silman S, Gelfand SA, Howard JC, Showers TJ (1982) Clinical application of the bivariate plotting procedure in the prediction of hearing loss. Scandinavian Audiology 11: 115-124. In Gelfand SA (1984) The contralateral acoustic reflex threshold. In Silman S (1984) The Acoustic Reflex: Basic Principles and Clinical Applications, Academic Press, Inc., Orlando, Florida, USA, 137-180.

96. Silman S, Popelka GR, Gelfand SA (1978) Effect of sensorineural hearing loss on acoustic stapedius reflex growth functions. Journal of the Acoustical Society of America 64: 1406-1411. In Gelfand SA (1984) The contralateral acoustic reflex threshold. In Silman S (1984) The Acoustic Reflex: Basic Principles and Clinical Applications, Academic Press, Inc., Orlando, Florida, USA, 137-180.

97. Stach BA, Jerger JF (1987) Acoustic reflex patterns in peripheral and central auditory system disease. Seminars in Hearing 8(4): 369-376. 
98. Strasser DH (1975) Contralateral and ipsilateral acoustic reflex latency measures in various otologic pathologies (PhD Dissertation). Salt Lake City, Utah: University of Utah. In Qiu W, Stucker F (1998) Characterization of acoustic reflex latency in normal hearing subjects. Scandinavian Audiology 27(1): 43-49.

99. Terkildsen K (1960) The intra aural muscle reflexes in normal persons and in workers exposed to intense industrial noise. Acta Otolaryncologica 52: 384-396. In Hannley M (1984) Immittance Audiometry. In Jerger J (1984) Hearing disorders in adults. College Hill Press, California, USA, 56-79.

100. Updike CD, Epstein A (1986) Characteristics of acoustic reflex in response to narrow bands of noise. J aud Res 26: 147-156. In Qiu W, Stucker F (1998) Characterization of acoustic reflex latency in normal hearing subjects. Scandinavian Audiology 27(1): 43-49.

101. Van Camp KJ, Vanpeperstraete PM, Creten WL, Vanhuyse VJ (1975) On irregular acoustic reflex patterns. Scandinavian Audiology 4: 227-232. In Lilly DJ (1984) Evaluation of the response time of acoustic immittance instruments. In Silman S (1984) The Acoustic Reflex: Basic Principles and Clinical Applications, Academic Press, Inc., Orlando, Florida, USA, 101-133.
102. Wilson RH (1979) Factors influencing the acoustic immittance characteristics of the acoustic reflex. Journal of Speech and Hearing Research 22: 480-499.

103. Zakrisson JE, Borg E, Blom S (1974) The acoustic impedance change as a measure of stapedius muscle activity in man: a methodological study with electromyography. Acta Otol 78: 357-364. In Gelfand SA (1998) Hearing: An introduction to psychological and physiological acoustics. ( $3^{\text {rd }}$ edn.). Marcel Dekker, New York, USA, 83-113.

104. Zwislocki JJ, Feldman AS (1970) Acoustic impedance of pathological ears. ASHA Monpgraphs pp.15. In Gelfand SA (1984) The contralateral acoustic reflex threshold. In Silman S (1984) The Acoustic Reflex: Basic Principles and Clinical Applications, Academic Press, Inc., Orlando, Florida, USA, 137-180.

105. Zwislocki MM (1960) Theory of temporal auditory summation. Journal of the Acoustic Society of America 32: 1046-1060. In Moller AR (1984) Neurophysiological basis of the acoustic middle ear reflex. In Silman S (1984) The Acoustic Reflex: Basic Principles and Clinical Applications, Academic Press, Inc., Orlando, Florida, USA, $1-30$.

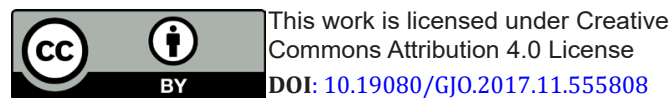

\section{Your next submission with Juniper Publishers} will reach you the below assets

- Quality Editorial service

- Swift Peer Review

- Reprints availability

- E-prints Service

- Manuscript Podcast for convenient understanding

- Global attainment for your research

- Manuscript accessibility in different formats ( Pdf, E-pub, Full Text, Audio)

- Unceasing customer service

Track the below URL for one-step submission https://juniperpublishers.com/online-submission.php 